\title{
Building an Instrument for Measuring Academic Administrator and Faculty Member Perceptions of the Workload Allocation Process as it Applies to Higher Education
}

Theodore Nelson Pauls

West Virginia University

Follow this and additional works at: https://researchrepository.wvu.edu/etd

\section{Recommended Citation}

Pauls, Theodore Nelson, "Building an Instrument for Measuring Academic Administrator and Faculty Member Perceptions of the Workload Allocation Process as it Applies to Higher Education" (2013). Graduate Theses, Dissertations, and Problem Reports. 364.

https://researchrepository.wvu.edu/etd/364

This Dissertation is protected by copyright and/or related rights. It has been brought to you by the The Research Repository @ WVU with permission from the rights-holder(s). You are free to use this Dissertation in any way that is permitted by the copyright and related rights legislation that applies to your use. For other uses you must obtain permission from the rights-holder(s) directly, unless additional rights are indicated by a Creative Commons license in the record and/ or on the work itself. This Dissertation has been accepted for inclusion in WVU Graduate Theses, Dissertations, and Problem Reports collection by an authorized administrator of The Research Repository @ WVU.

For more information, please contact researchrepository@mail.wvu.edu. 


\title{
Building an Instrument for Measuring Academic Administrator and Faculty Member Perceptions of the Workload Allocation Process as it Applies to Higher Education
}

\author{
Theodore Nelson Pauls
}

A dissertation submitted to the College of Education and Human Services at West Virginia University in partial fulfillment of the requirement for the degree of Doctor of Education in Educational Leadership Studies (Higher Education)

Paul E. Chapman, Ph.D., Chair

Ernest R. Goeres, Ph.D.

Jerry D. Jones, Ph.D.

Connie L. Myer, Ed.D.

Anne H. Nardi, Ph.D.

Department of Curriculum and Instruction/Literature Studies

Morgantown, West Virginia

2013

Keywords: Workload Allocation, Perception Instrument, Higher Education, Faculty Perceptions, Faculty Workload, Academic Administrator Perceptions 


\title{
Abstract \\ Building an Instrument for Measuring Academic Administrator and Faculty Member Perceptions of the Workload Allocation Process as it Applies to Higher Education
}

\author{
Theodore Nelson Pauls
}

The focus of this study was to build and test an instrument that measures academic administrator and faculty member perceptions of the workload allocation process. The primary findings of this study are founded in the initial use of the developed instrument. Sixty academic administrators and 320 faculty members from colleges of education at 19 high research universities in the southeastern United States were sent the 35 item instrument via electronic survey. Survey items were placed into five unidentified domains related to the workload allocation process. Based on the data from the survey, t-tests were conducted for each domain and for the composite mean score to determine whether statistically significant differences existed between academic administrators' and faculty members' perceptions of the workload allocation process.

Results indicated the two groups differ in their perceptions sporadically throughout the instrument, but consistently within one domain. 


\section{Contents}

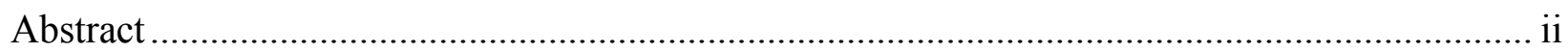

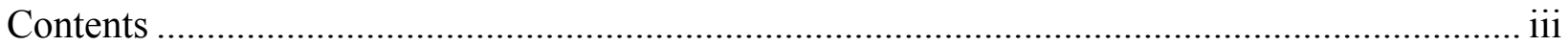

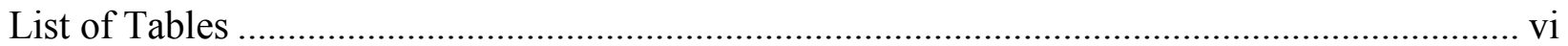

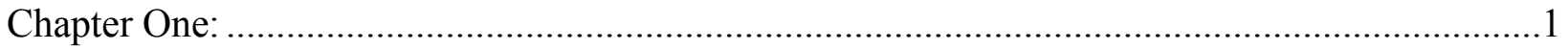

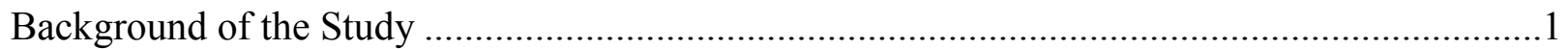

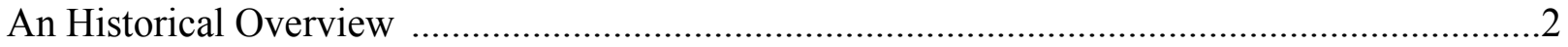

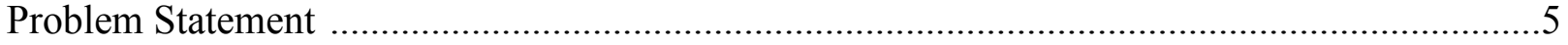

Purpose and Significance of the Study ......................................................................

General Perspective of the Quantitative Overview of the Method ..........................................9

Research Questions and Hypotheses ............................................................................ 10

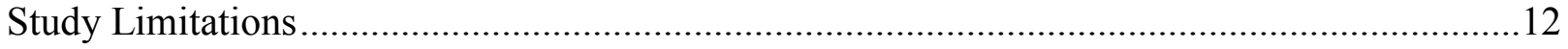

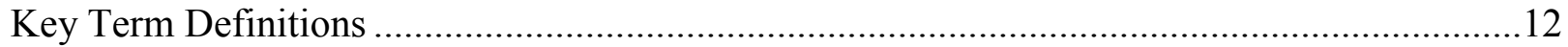

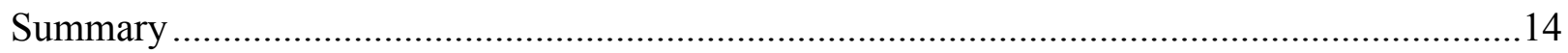

Chapter Two: Review of Pertinent Literature......................................................................

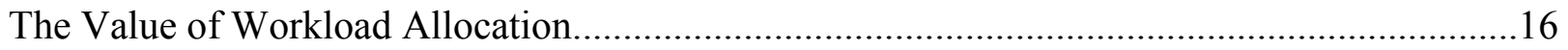

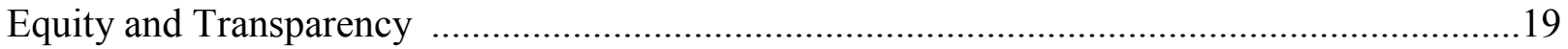

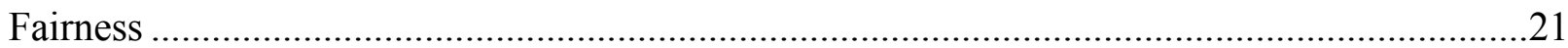

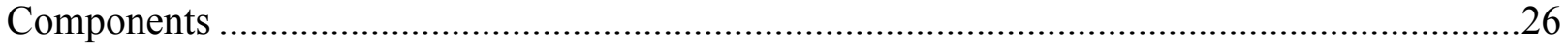

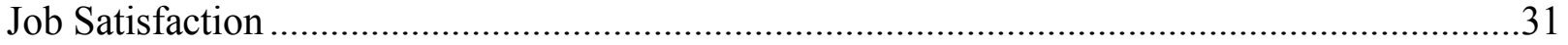

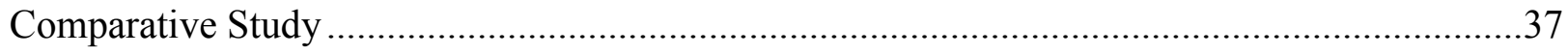




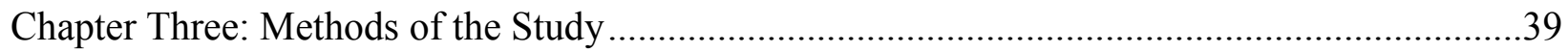

Research in Context of Workload Allocation Processes ......................................................39

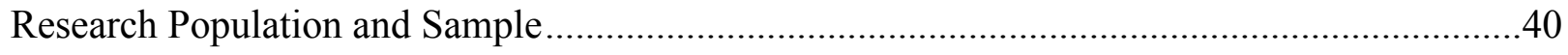

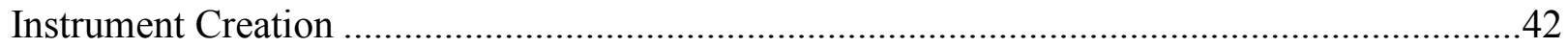

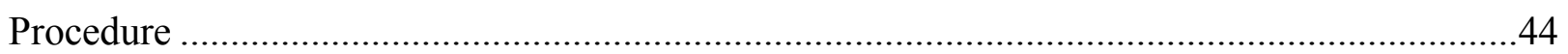

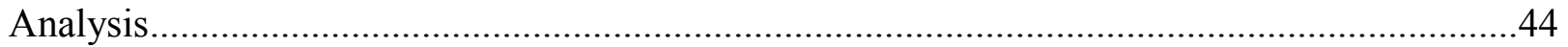

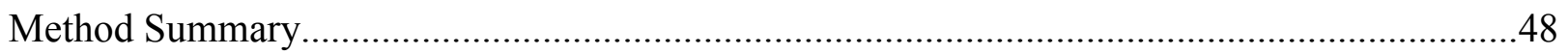

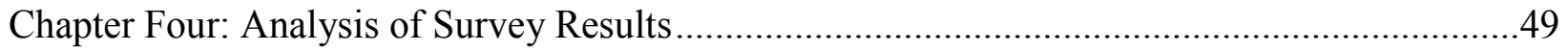

Survey Response Rates and Participant Demographics...................................................49

Statistical Analysis by Domain and Composite Mean Score.................................................50

Domain 1: Perceptions of Workload Allocation Process Value ...........................................50

Domain 2: Perceptions of Workload Allocation Process Equity and Transparency ..................52

Domain 3: Perceptions of Workload Allocation Process Fairness ........................................54

Domain 4: Perceptions of Workload Allocation Process Components ..................................55

Domain 5: Perceptions of Workload Allocation Process Effects on Job Satisfaction................57

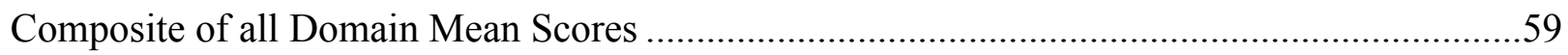

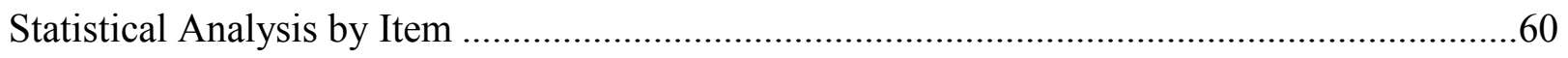

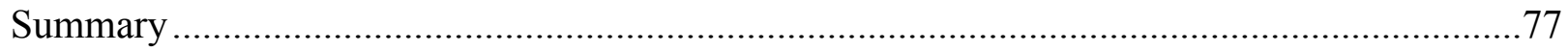

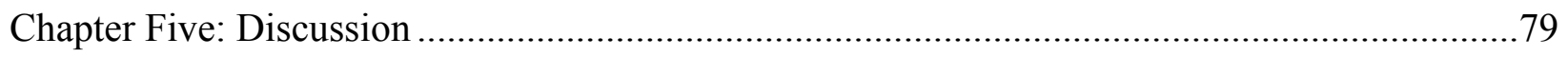

Explanation of Significantly Different Responses........................................................... 80

Implications for Higher Education Leaders .............................................................. 82

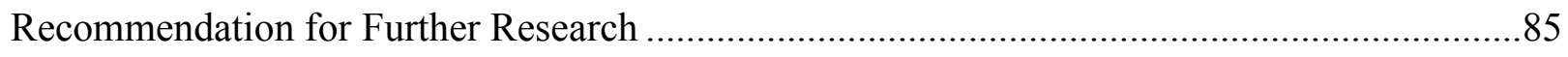




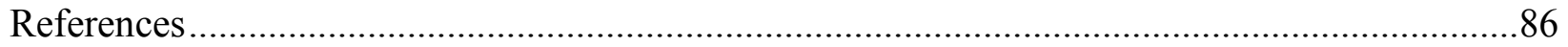

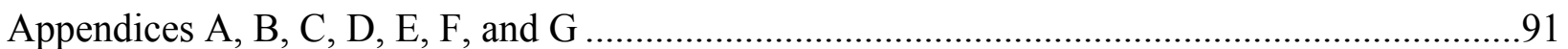

Appendix A: Domains and Items ………………….......................................................92

Appendix B: Pauls \& Chapman Instrument for Measuring Perceptions of Workload

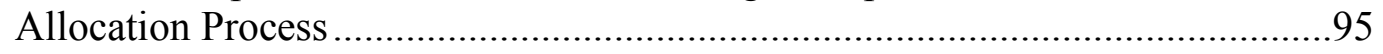

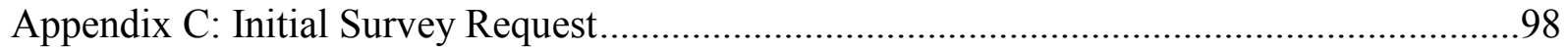

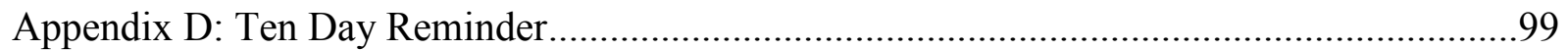

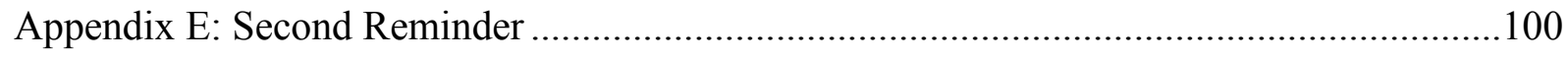

Appendix F: Two Weeks Remaining Reminder ...................................................................101

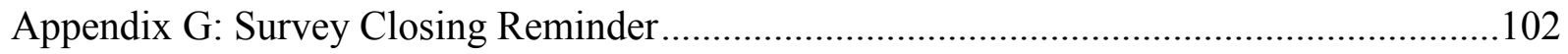




\section{List of Tables}

Table

Page

1 Education Doctorate-Granting Universities with High Research Activity in Southeast United States

2 Variables, Label Descriptions, and Value Codes

3 Institutional Years of Service

$4 \quad$ Items Included in Perceptions of Workload Allocation Process Value 51

$5 \quad$ Mean Scores for Perceptions of Workload Allocation Process Value

6 t-test for Perceptions of Workload Allocation Process Value

7 Items Included in Perceptions of Workload Allocation Process Equity and Transparency

8 Mean Scores for Perceptions of Workload Allocation Process Equity 53 and Transparency

9 t-test for Perceptions of Workload Allocation Process Equity and Transparency

10 Items Included in Perceptions of Workload Allocation Process Fairness 54

11 Mean Scores for Perceptions of Workload Allocation Process Fairness 55

12 t-test for Perceptions of Workload Allocation Process Fairness 55

13 Items Included in Perceptions of Workload Allocation Process 56 Components

14 Mean Scores for Perceptions of Workload Allocation Process 57 Components

15 t-test for Perceptions of Workload Allocation Process Components 57

16 Items Included in Perceptions of Workload Allocation Process Effects 58 on Job Satisfaction 
Table

17 Mean Scores for Perceptions of Workload Allocation Process Effects on Job Satisfaction

18 t-test for Perceptions of Workload Allocation Process Effects on Job Satisfaction

19 Composite Mean Scores for Process of Workload Allocation Process 60

20 t-test for Composite Mean Scores $\quad 60$

21 Mean Scores for Item 1 61

22 t-test for Item $1 \quad 61$

$23 \quad$ Mean Scores for Item $8 \quad 64$

$24 \quad$ t-test for Item 8

25 Mean Scores for Item $9 \quad 65$

26 t-test for Item $9 \quad 65$

27 Mean Scores for Item $10 \quad 66$

$28 \quad$ t-test for Item $10 \quad 66$

29 Mean Scores for Item 11 67

$\begin{array}{lll}30 & \text { t-test for Item } 11 & 67\end{array}$

$31 \quad$ Mean Scores for Item $12 \quad 68$

32 t-test for Item $12 \quad 68$

33 Mean Scores for Item $13 \quad 69$

34 t-test for Item $13 \quad 69$

35 Mean Scores for Item $20 \quad 71$ 
Table

$36 \quad$ t-test for Item 20

$37 \quad$ Mean Scores for Item 31

$38 \quad$ t-test for Item 31
Page

72

75

76 


\section{Chapter One: Introduction of the Study}

\section{Background of the Study}

For centuries, scholars who have devoted their lives to work in higher education have enjoyed a standard of professionalism unmatched by nearly every other career. The value of their services was supported with little or no question. In recent years, however, professors have found themselves being held accountable to a variety of stakeholders, both internally and externally. During times of economic downturns, higher education institutions are not excused from stakeholders' financial sensitivity. The need to document, or account for, the efficiency of the institution and its employees becomes paramount.

When Frederick Taylor conducted his studies on efficiency of time in the workplace (Hersey, Blanchard, \& Johnson, 1996), he probably never envisioned its application to scholarly activities. But the workload allocation process in higher education is a direct result of the scientific management set forth by Taylor's work. Today most higher education institutions have an established workload allocation process, whether by discipline, department, or institutionwide. The protection once offered by the status of higher education institutions is no longer enough to guard them from the ravages of the recession and its impact on the financial wellbeing of universities. In 2008, endowments at U.S. universities fell over 25 percent on average (Clark, 2009). Many universities have avoided cutting aid provided by endowments and have instead reduced the number of faculty or reduced their pay, or have delayed major costs such as construction of new facilities. However, the values of endowment alone are not the only source of financial concern for universities. There are also many external concerns for university budgets. 
Moody's, a leading credit agency that rates the financial strength of various entities, predicted financial woes for universities as recessions affect (1) students' ability to pay for college, (2) reduced philanthropy, and (3) fewer grants. The reduced availability of credit during recessions makes borrowing for colleges more costly. Recessions cause states to cut higher education budgets due to decreased revenue. These reductions may mean fewer services offered by universities and fewer classroom seats for students (Clark, 2009). Despite the reductions, those willing to pay for college do so with the expectation of more opportunities and more lifetime earnings in an increasingly competitive market. They also, along with legislators, governing boards, parents, taxpayers, and other stakeholders, do so with increased expectations of accountability for faculty members to describe exactly what they provide (Mayes, 1998).

\section{An Historical Overview}

Until the $19^{\text {th }}$ century, it was customary for all students in higher education to take the same classes in the same sequence. As they completed one area of the curriculum, they moved on to another. In 1869, the centuries-old tradition would change. At the direction of Harvard President Charles Eliot, students were able to choose, or elect, a number of classes in their curriculum to match their personal curiosity and aspirations. The introduction of this freedom led to the need for assessing the student's progress for a variety of classes. In doing so, it also became necessary to evaluate the courses for some equitable measurement of individual student progress (Heffernan, 1973). This in turn created some measurement for faculty work in teaching.

Because the origins of faculty duties were traceable to individual courses, it was the course that provided the standard for measurement for faculty teaching load. Nearly every institution accepted one course to be deliverable in lectures to last three hours per week. This 
number was deemed optimal to teaching and student learning (Ehrlich, 2003). A credit was assigned for each hour of lecture, thereby creating three credit-hours as the standard for one course. Depending on the university calendar, faculty members were assigned a minimum number of credit-hours or teaching obligations. Although the measurement remains even today as credits, the term credit may be interpreted as the number of courses to be taught, particularly in referring to the notion of faculty course load, or workload. Ehrlich (2003) refers to the term credit as contact time in the classroom between students and faculty. In any definition, credits have become an important standard for measuring faculty workload.

The evaluation of courses naturally led to a comparison of what each faculty member taught by course load, and as long as the courses themselves were quantitatively equal concerning credit-hours, so was the measurement of individual faculty member's courses to be taught, or course load. Centuries of adaptation to course delivery methods, course requirements, laboratory requirements, various levels of degree confirmation, research expectations, fundraising and grant writing made the comparison of faculty member contributions in teaching more difficult to measure. Course load by teaching was only one expectation of faculty work productivity.

Through time, faculty duties became identified into three fundamental areas; teaching, research, and service. In a 1979 survey of faculty, Ladd determined that the faculty did not distribute duties equally among the three areas, with more emphasis on teaching than on scholarship. Further, depending upon where faculty members were in their careers, the distribution was even more skewed, with more senior faculty members spending an even greater proportion of their time on teaching. Career status was not the only factor affecting workload; 
outside stakeholders were questioning the work of universities and faculty.

Early in the 1970's, Wyant and Morrison (1972) determined that a crisis in higher education had been created due to society's perceptions of university missions and confusion over faculty roles within the university. With little to no understanding of what faculty members did beyond the classroom, external stakeholders could not be expected to know how much of faculty members' time was required for the tasks. It was that very misunderstanding that led institutions to develop some sort of accounting for the work habits of faculty. In addressing the concerns of outsiders, universities could begin to assess their own curriculum and requirements to efficiently and effectively administer that curriculum from both a fiscal and manpower basis and for both current and future needs. But universities did not act in solitude. Societal concerns for accountability were being examined increasingly by researchers and state agencies.

In 1992, the Colorado State Higher Education Executive Officers conducted a study out of interest in higher education productivity and expenses (Russell, 1992). The timing of the research matched a national concern. In the same year, Heydinger and Simsek (1992) examined faculty productivity due to the demand for accountability in higher education. A 1998 study (Mayes) determined that in the period between 1993 and 1994, faculty workload was the research subject in at least 24 state higher education commissions. In the same era, James Fairweather (1996) authored a book that examined public distrust of the work in which faculty were engaged and in higher education overall. Not surprisingly, Fairweather discovered economic conditions as a primary factor in the attention faculty work was receiving. Problems with the process of reporting workload allocation were beginning to emerge as the development of allocation models continued to grow. 
Stakeholders had sought for an evaluation of faculty work and contributions. The use of internal administrative records could help account for some metrics, such as student/faculty ratios, cost per faculty member, and departmental and instructional costs (Mayes, 1998). Another internal source was the surveys faculty members would complete at administrative request to describe how they spent their time and how it related to any workload contract. Externally, faculty began completing surveys administered by state agencies. However, the process of evaluating became reliant on self-reported data from faculty members rather than an external evaluation of faculty contributions (Seaberg, 1998). Researchers concluded that the hierarchical nature of data weakened research on faculty productivity (Porter \& Umbach, 2001).

In 2008, Robert Green reported that for more than 15 years, studies and evaluative comment had been published regarding the changing nature of faculty roles in higher education. Green cautioned that only graduate faculty had reported on workload, and that data on tenure and promotion had been collected only from academic administrators. At the core of the research was the process of the development of models to measure or allocate faculty workload (Vardi, 2009). In his conclusion, Robert Green (2008) suggested an examination of the relationship of workload priorities versus work role priorities, particularly from the perspective of graduate faculty members. What had not been examined was the perception faculty and administration had in the workload allocation process. That phenomenon is the focus of this research.

\section{The Problem Statement}

There is considerable anecdotal evidence of how people create and distribute workload allocation processes for higher education institutions, but not how workload allocation processes are perceived. Describing and judging the work of faculty can be difficult. Additionally, the 
need to do so remains questionable among some faculty members and academic administrators. As a perennial topic of debate, the issue of faculty workload has reached as far as the United States Supreme Court.

When the Ohio Board of Regents found that professors' time in the classroom had decreased an average of ten percent over a decade, the state legislature enacted a law to increase the maximum amount of time teachers could spend in the classroom from 12 to 15 hours per quarter (Wilson, 1999). The new law allowed Central State University to adopt a new workload policy without input from the faculty union. Soon after, the American Association of University Professors filed suit with the Ohio Supreme Court that the law violated both state and federal constitutions because it singled out professors as the only public employees not afforded the right to bargain over workloads. In a close decision, 4-to-3, the Ohio Supreme Court decided in favor of the AAUP and professors (Wilson, 1999). Upon appeal, the United States Supreme Court reversed the lower court decision, thereby upholding the Ohio law. The Supreme Court then remanded the case back to the Ohio State Supreme Court to hold to the U.S. Supreme Court decision or to hear the case again and issue a new ruling. Upon review, the Ohio Supreme Court reversed its earlier decision and decided the new law did not violate the state constitution (Fisher, 1999). The Ohio case represents the potential severity of challenges faced by institutions across the country every year.

Because of the nebulous development process and ambiguity of workload allocation processes, faculty members and academic administrators may perceive the role and outcome of workload allocation in a manner that leads to tension and resentment. If such tension exists, the result is counterproductive for all parties. Further, if faculty and academic administrators do not 
feel comfortable in the development and use of or need for workload allocation processes, consistency of implementation is problematic. The problem is the ill-defined nature of the workload allocation process leads to a counterproductive environment for faculty and academic administrators in higher education institutions.

If there were a better understanding of how faculty and academic administrators perceive the workload allocation process, decision makers could improve the process development and implementation. The workload allocation process will continue to be a misunderstood phenomenon for higher education institutions and their stakeholders until an instrument exists to measure these perceptions.

\section{Purpose and Significance of the Study}

Understanding the perceptions of academic administrators and faculty about the workload allocation process may lead to better workload allocation development, which in turn may compensate for perceived shortcomings. This study focuses on the creation of an instrument to measure faculty and academic administrator perceptions of the workload allocation process. The overriding purpose is to equalize faculty work force productivity across distinguishable units defined by the institution. In doing so, the workload allocation process should become a better understood phenomenon and more equitable, fair, and streamlined for people to use for an assessment of professional growth and an accounting of productivity.

Faculty members at higher education institutions benefit from a well-conceived and implemented workload allocation process by fully understanding the institutional expectations. They also know that the work they do, although different from others in the university, is valued at an equitable level to all other faculty members. More precisely, a faculty member in a college 
of business measured by the same workload allocation process as a faculty member in the college of engineering should not have unequal workloads.

Higher education institution academic administrators benefit by equalizing the expectations of all faculty members both within and between departments. Parity of contributions to workload would be well defined and less divisive. Further, faculty evaluation and assessment would become more easily measured. The notion of many hands make light work is applicable as long as the work is equitable.

University officials at the central office administration benefit for accreditation purposes, in the pursuit of raising institutional standing in the Carnegie classification system, and in avoiding potential lawsuits from a disgruntled faculty member. An improved workload allocation process also may aid in the university's achieving and maintaining accreditation.

Accrediting agencies benefit from the point of consistency within the institution and between institutions in the same system. With a well-defined standard of faculty workload expectations to augment standards of other faculty requirements (e.g., degrees, professional standards, etc.), the accreditation process may become more clarified.

Stakeholders would also benefit from an improved workload allocation process. Legislators would know that the tax dollars allocated for higher education would be accounted for by a standardized measure. Students benefit by knowing the faculty members from whom they learn are not overburdened and that they will receive their education from a professor with a high level of expertise in the field.

A workload allocation process that is well conceived and implemented is clearly beneficial across multiple platforms. If we understand the perceptions of those most closely 
involved with the process of workload allocation, we would be able to develop a better process for allocating faculty workload. In order to understand the workload allocation process perceptions of faculty and academic administrators, however, we must first develop an instrument to measure those perceptions.

\section{General Perspective of the Quantitative Overview of the Method}

This is a quantitative study designed for building an instrument to measure academic administrator and faculty perceptions of the workload allocation process. The study is centered on building an instrument and seeking feedback from both faculty and academic administrators to hone the instrument. The instrument was piloted by conducting a cross-sectional survey for data collection (Creswell, 2003) from faculty and academic administrators at Carnegie Classified High Research institutions in the southeast region of the United States.

In developing the instrument, the primary focus was on translating the information goals into questions, or items, included in the instrument (Sudman \& Blair, 1998). The instrument development addressed topics of reliability, validity, ordering of questions, wording of questions, software support for analyzing results, and subject matter to be included in questions (Burns \& Bush, 2008; Suskie, 1996).

The population for this study is academic administrators and full-time faculty members within colleges of education offering doctorate degrees at Carnegie Classified High Research Institutions in the southeast region. A cluster sample was selected from both faculty members and academic administrators representing each of the institutions of the population. Cluster samples maintain the probability sampling method desired in quantitative studies while ensuring each of the institutions was represented (Burns \& Bush, 2008). The instrument was administered 
electronically. After ten days had passed from the initial distribution of the instrument, a reminder notice was sent to participants who had not yet responded. A second reminder was sent to participants who still had not completed the survey after two more weeks. After another two weeks had passed, a third reminder was sent to those who had not yet responded. A final reminder was sent the morning of the survey's termination, after which the data from the completed surveys were analyzed.

This study used an instrument created to compare perceptions of faculty and academic administrators regarding the workload allocation process. The instrument uses a Likert-type scale in order to give scores ranging from 1 to 5 . Because the study compares two groups for differences, t-tests were conducted for inferential statistics for each item under each domain, based on the mean score from respondents. The next section contains the research questions and domains from which the instrument was developed.

\section{Research Questions and Hypotheses}

In order to measure faculty and academic administrator perceptions of the workload allocation process, this study focused on five domains related to institutional workload.

Domain 1: Perceptions of Workload Allocation Process Value.

RQ1: Is there a difference in how faculty and academic administrators perceive the value of the Workload Allocation Process?

$\mathrm{H}_{0}$ : There is no statistically significant difference in Domain 1 scores in a comparison of academic administrator and faculty responses.

$\mathrm{H}_{1}$ : There is a statistically significant difference in Domain 1 scores in a comparison of academic administrator and faculty responses. 
Domain 2: Perceptions of Workload Allocation Process Equity and Transparency. RQ2: Is there a difference in perception between how academic administrators and faculty perceive the equity and transparency of the workload allocation process?

$\mathrm{H}_{0}$ : There is no statistically significant difference in Domain 2 scores in a comparison of academic administrator and faculty responses.

$\mathrm{H}_{1}$ : There is a statistically significant difference in Domain 2 scores in a comparison of academic administrator and faculty responses.

Domain 3: Perceptions of Workload Allocation Process Fairness.

RQ3: Do academic administrators and faculty perceive the fairness of the workload allocation process the same?

$\mathrm{H}_{0}$ : There is no statistically significant difference in Domain 3 scores in a comparison of academic administrator and faculty responses.

$\mathrm{H}_{1}$ : There is a statistically significant difference in Domain 3 scores in a comparison of academic administrator and faculty responses.

Domain 4: Perceptions of Workload Allocation Process Components.

RQ4: Do academic administrators and faculty perceive the value of the components of the workload allocation similarly?

$\mathrm{H}_{0}$ : There is no statistically significant difference in Domain 4 scores in a comparison of academic administrator and faculty responses.

$\mathrm{H}_{1}$ : There is a statistically significant difference in Domain 4 scores in a comparison of academic administrator and faculty responses. 
Domain 5: Perceptions of Workload Allocation Process Effects on Job Satisfaction.

RQ5: Do academic administrators and faculty view the relationship between workload and job satisfaction in the same way?

$\mathrm{H}_{0}$ : There is no statistically significant difference in Domain 5 scores in a comparison of academic administrator and faculty responses.

$\mathrm{H}_{1}$ : There is a statistically significant difference in Domain 5 scores in a comparison of academic administrator and faculty responses.

\section{Study Limitations}

This study reflects the perceptions of a regional population of academic administrators and full-time faculty in colleges of education at institutions classified as High Research in the Carnegie classification system. Results may vary by region or by other Carnegie classification levels. In making the distinction between administration and faculty, department chairs are considered academic administrators for the purpose of this study. In practice, department chairs represent a hybrid between academic administrator and faculty, because the work required for the position crosses into the description of both categories.

\section{Key Term Definitions}

Academic administrator - Individuals responsible for an academic program, an academic department, or school or college of education within the university.

Components of Workload Allocation - Teaching, Service, and Research or Scholarship Domain - The specific area of focus under which each element of study falls.

Faculty - Permanent, full-time, members of an institution whose role is specific to an area of academic specialization, at least part of which is dedicated to teaching. 
Institutional Cost Containment - That part of a university's budgeting process which is accountable to the maintenance or reduction in expenses.

Null Hypothesis - a statement of a non-statistically significant relationship between two independent variables.

Recession - A period of at least two consecutive declining quarters of Gross Domestic Production.

Scholarship - The creation, discovery, advancement, or transformation of knowledge. Includes peer-reviewed articles, authored or edited books, published book chapters, external funding obtained, and non-refereed publications (Freedenthal, Potter, \& Grinstein-Weiss, 2008).

Value of Workload Allocation - The belief that some presence of workload allocation is preferable to its absence.

Workload - How faculty members spend their time on a weekly basis, sometimes defined contractually (Mayes, 1998).

Workload Allocation Equity and Transparency - a measure of whether the process of allocating workload is conducted openly and that faculty member workloads are evenly distributed.

Workload Allocation Fairness - a measure of whether the process of allocating workload is conducted without prejudice or favoritism and that any uneven distribution is rational.

Workload Allocation Process - the method used to develop and implement the expectations and responsibilities of faculty in higher education. 


\section{Summary}

The phenomenon of faculty workload at institutions of higher education is confounding when it comes to faculty and academic administrator perceptions. The focus of this study was to build and test an instrument that measures academic administrator and faculty perceptions of the workload allocation process. The primary findings of this study are founded in the initial use of the developed instrument.

Chapter One of the study contains background information of workload allocation processes, a problem statement specific to the study, statements supporting the significance of the study, and a brief overview of the methodology, including research questions and how the survey was created and administered. The opening chapter also includes a section on study limitations and key term definitions.

Chapter Two is a selective review of pertinent literature. As a framework for the entire document, the chapter provides a research lens for both current and historical frames of reference. The chapter presents a convergence of theoretical and empirical literature as it relates to the need for, and development of, workload allocation processes for higher education faculty. Chapter Two summarizes the connection among the problem statement, the significance of the study, and the research questions set forth in Chapter One.

Chapter Three describes the specific methodology used in the study. Among the subjects of the chapter are a complete description of the design of the study, the population and sampling methodology, a complete and detailed description of how the instrument was built and pre-tested, and a step-by-step description of the data acquisition and analysis procedures. 
Chapter Four is a statistical analysis of data collected from academic administrators' and faculty members' responses to perceptions of the workload allocation process. The chapter contains a summary of respondent demographics, an analysis of each domain and composite mean score, and an analysis of each individual item.

Chapter Five focuses on a discussion of the study and explanations of the responses that yielded significant differences. The chapter also contains a section with recommendations for future research. 


\section{Chapter Two: Review of Pertinent Literature}

\section{The Value of Workload Allocation}

With pressure from multiple sources to account for how faculty members allocate their work, higher education institutions must determine the best way to measure and report productivity by different standards. At the two extremes, workload allocation can be determined entirely by institution administration or by individual faculty members. Between these two options lies any combination of academic administrator and faculty input. The obstacle is that it is very difficult to measure the multiple variables with many definitions of what work faculty members have and how they perceive their work. Further, some faculty productivity is difficult to quantify, such as class preparation time, committee obligations, presentations, and conference attendance. Additionally, it is a challenge to reconcile fixed variables such as class size, academic programs, and university mission with administration definitions of productivity and the various views faculty members have of their own work. ("Research on Faculty," 2002).

Academic administrators have a notion of what they perceive faculty members should be doing. Academic administrators also must balance institutional needs. They want some input into faculty work descriptions, but they also want to realize the most productivity out of the academic staff. In the end, the inherent difficulty is that faculty and administration frequently are confronted with separate realities. If the internal difficulties of workload allocation were not difficult enough, the addition of external stakeholders further complicates the process.

Other contributing participants to workload allocation are state legislatures. Although these bodies rarely dictate direct workloads, they do establish what must be included in the workload (Ehrlich, 2003). For example, when the State of Ohio Board of Regents assigned a 
committee to develop standards and guidelines for faculty workload, the outcome was a document that addressed different teaching requirements based on the degrees the institutions conferred (Ehrlich, 2003). The range of teaching as a percent of total department workload was from 50 percent for institutions offering baccalaureate, masters, and doctoral programs to 90 percent for those offering associate or two-year degrees. By dictating workload requirements as an external entity, legislatures frequently cause faculty members to feel the need to defend their autonomy and academic freedom. When the impetus is internal, faculty and academic administrators have the ability to be more flexible in the workload allocation design.

This flexibility of internal workload allocation development allows professors to extend their interests and is preferred by both faculty members and academic administrators (June, 2008). Vardi (2009) writes that the most successful workload allocation processes are those that are developed through transparent and collaborative efforts between faculty members and academic staff. It is important to remember, however, that department needs outweigh the desires of faculty members when developing workloads (June, 2008). The responsibility for shaping faculty roles within the constraints of institutional needs is shared. Academic administrators and individual faculty members should be active in managing the resources of faculty expertise and other needs of the institution (Houston, Meyer, and Paewai, 2006). Even in practice, however, the outcome of this shared responsibility is not always desirable.

In efforts to share responsibility and to be transparent and equitable, administrative heads agree that the workload models they develop are helpful and valuable, regardless of the type of model they have developed (Vardi, 2009). However, also independent of the type of workload model developed, faculty members do not always feel that transparency and equity are occurring 
in the workload process. Even so, faculty members agree that it had been the goal of the administration to develop workload models that would be transparent and equitable. Academic administrators can alleviate the sensitivity that the models they have developed are not achieving the goals they had sought.

Himes (2005) suggests that by involving academic staff in planning and making decisions on the development of workload models, academic administrators will help to create an environment that will help satisfy the faculty. Most academic administrators claim that they do, in fact, support the inclusion of academic staff in determining faculty workload (Vardi, 2009). In the same spirit, however, academic administrators maintain an imbalance between the desires of faculty and the needs of administration or the institution's needs. Correcting and maintaining disproportionate workload allocation while recognizing individual faculty members' preferences and unique skills can be a challenge to academic administrators. Further, the actual time it takes to complete tasks is often not calculated but estimated, and the estimations are frequently short of the realities of time consumption. According to both academic administrators and faculty, common areas that contribute to poor time allocation are administrative duties, change initiatives, technology, and inefficient processes.

In light of university mission, school and department needs, and faculty desire, it is imperative to proceed fairly with workload allocation; the success or failure to do so can affect the quality of the program, faculty morale, and student contentment ("Managing Faculty Workload," 2005). Because of the importance of the workload allocation process and its impact on faculty morale and academic integrity, Lumpkin (2004) advocates solid skills as a leader and 
the ability to manage conflict as highly important qualifications for academic administrators. Conflict should be reduced if the process is perceived as equitable.

\section{Equity and Transparency}

Houston et al. (2006) maintains that there is limited literature on varying approaches to workload allocation, and that there are no conclusive, clear guidelines, and no consequential standards to workload development. Nevertheless, the demand for equity among faculty members comes from many sources. Academic administrators, legislators, higher education commissions, and accrediting agencies are among those who, in addition to faculty members themselves, now insist on an equitable distribution of faculty workloads. This mandate has been an impetus for the development of workload allocation processes across most public institutions (Ehrlich, 2003). Universities, however, are complex organizations (Houston et al.) with a variety of faculty expertise, institutional missions, accreditation criteria, student needs, and research demands. Attempts to be transparent and equitable in standardizing workload allocation while confronting different realities can be challenging, but it is also one of the academic administrators' important tasks (“Managing Faculty Workload,” 2005).

Those responsible for maintaining equity among faculty workloads maintain that not all workload allocation reflects the actual time it takes to complete a task and, therefore, the process naturally gives some staff a preferential outcome over others (Vardi, 2009). Workload allocation processes that include staff collaboration and for which faculty view as transparent are more successful than those that do not. Additionally, faculty members receive more favorably those workload allocation processes that undergo regular review, are more transparent, and are equitable. Still, some research has shown that despite the fact that a well-developed workload 
allocation process improves workload equity, some faculty members still experience work overload (Vardi, 2009). The problem remains that, even with best practices, faculty and academic administrators still may not be able to reach a purely equitable workload arrangement.

Many academic administrators admit that transparency and equity is a primary goal of workload allocation, but that other factors impact their ability to be equitable. In addition to faculty expertise and availability, academic administrators consider levels of appointment, competence, experience, career aspirations, preferences for courses, and student preferences (Vardi, 2009). These factors are also recognized by faculty members who also admit that academic administrators attempt to be transparent and equitable, but that the outcomes in their departments fall short of the goal. Although many faculty members recognize administrative concern for faculty well-being, research indicates not all academic administrators agree that the primary goal of workload allocation is equity.

According to Lau (1996), the main objective of workload allocation is to accommodate institutional needs, both present and future, for accreditation and continuous improvement. When workload allocation triggered by institutional need over transparency and equity results in faculty workload increases, academic staff tend to begin comparing their own workloads to their colleagues' workloads and to begin to examine whether the process is equitable (Durham, Merrit, \& Sorrell, 2007). Need driven workload allocation is frequently not understood by faculty members, resulting in an increased call for a workload allocation process that addresses perceptions of inequity. 


\section{Fairness}

The need for higher education institutions to reconcile institutional needs with various definitions of productivity, including faculty and legislative, is inescapable ("Research on Faculty," 2002). In instances in which faculty members have expressed dissatisfaction with workload allocation, faculty pushed for the development of formulas to determine workload fairness. Through the creation and publication of workload formulas, faculty members experience improved morale, more sense of control, and an increased awareness of their colleagues' workloads and accountability (Voignier, Hermann, \& Brouse, 1998). At the base of workload formulas is the norm most commonly referred to as the course (Ehrlich, 2003). The academic administrative position most closely in tune with the need for departmental courses and with faculty availability is the department chair.

A primary responsibility of the department chair is managing the workload of the department's faculty members. The chair must balance both student and faculty satisfaction while maintaining a quality academic program ("Managing Faculty Workload," 2005). The question of how to best go about achieving that mandate is not easily answered. Literature does not provide a preferred approach and does not suggest any clear guidelines with known consequences (Houston et al., 2006). Empirical proposals do exist, however, with some general points from which to start.

Program reviews, assessment, and comparisons to peer programs may all be helpful in considering if workload adjustments are necessary (Lau, 1996; Sumner \& Brewer, 2006). Class enrollment sizes, committee membership and chairmanship, paper presentations, and scholarly publications are among additional considerations for department chairs in determining workload 
allocation. More intangible items, such as teaching quality, should also enter workload equations (“What's Driving Your," 2002). Chairs should also recognize that individual faculty members should not all be doing the exact same thing over their professional career. Opportunities for personal and professional development and growth must also be provided (June, 2008). Lastly, marketplace of other institutions should be a consideration in the development of departmental norms when developing workload expectations ("Managing Faculty Workload," 2005). Information from the department chairs' workload development process does not only flow downward. It should also be reported to those higher on the academic hierarchy.

Any workload assignments should be reported to the department chair's dean. An informed dean can examine workload allocation for any unusual or inefficient practices. As Ehrlich (2003) contends, credits assigned in faculty workloads are rarely planned or designed by the institution, thereby necessitating an additional level of review by the dean for fairness. Additionally, deans are usually more empowered in structuring more significant decisions in workload allocation. As chairs submit workload allocation data to the dean, the more senior academic administrator needs to outline a plan to evaluate inter-department faculty workloads. (Lau, 1996; "Managing Faculty Workload," 2005). However, many higher education institutions allow for the practices of departments and individual judgment to substitute for codified guidelines (Ehrlich, 2003). As data emerge for faculty workload and program needs, chairs and other academic administrators must define how to fairly evaluate faculty workload. They must also determine the primary purpose of workload allocation policies and models. Are they created to benefit the school, the academic staff, or both? 
Some research suggests that the primary purpose of workload policies is for the benefit of planning for both present and future needs of the school (Lau, 1996). In order to do so, faculty members must be evaluated in areas of teaching, research, and service. Others suggest that the focus of workload policies is to treat faculty fairly. No faculty member should receive favoritism, but faculty skills and preferences should be taken into consideration (Durham et al., 2007). Still other research indicates that faculty workload policies and models benefit both the institution and the faculty members. Attempts to objectively quantify faculty workloads in order to determine a fair and equitable allocation while allowing for departmental teaching needs and research needs is imperative (Durham et al., 2007). Even though attempts are made to be objective and quantitative in allocating workloads, questions remain as to the validity of the comparisons.

Use of the individual course as the standard starting point for workload comparisons is the tradition. This standard started when almost every course was delivered by a faculty member in a 50 minute lecture (Ehrlich, 2003). Most institutions use a three hour, or three-credit, course as the baseline for measuring faculty workload. The generally accepted three credit convention not only is used to measure faculty workload, but also as a measure of student learning. For the purpose of measuring faculty workload, the term credit-hour measures student-faculty contact hours in the classroom (Ehrlich, 2003). But because courses now differ in length, content difficulty, and academic levels, time requirements, there is the question of how to best compare credit-hours to other faculty activities.

Regardless of the process of allocating workload, difficulties emerge in determining what activities should be included and how they should be quantified. For example, teaching in a 
lecture format may not have a natural metric comparison to online teaching, academic duties, research, advising, or fieldwork supervision (Vardi, 2009). The time it takes to complete various tasks are frequently underestimated in workload allocation. Both academic administrators and faculty agree that increases in expected administrative duties of faculty, changing technology, inefficient processes, staffing shortfalls, and consulting work add to the overall allocation of workload to academic staff (Eunjoo \& Suhong, 2009; Vardi, 2009). Durham et al. (2007) found that release time for research and scholarship for both tenure and tenure-track faculty was one of three problems faculty identified as being unfair in comparison to credit-hours. The other two problems identified by Durham et al. (2006) were the lack of credit for serving as chair of a committee, either institutional or dissertation, and a failure to adjust workloads for faculty members enrolled in doctoral programs. The existence of these concerns lends credence to Vardi's (2009) research that criticizes workload allocation processes that inaccurately reflect time requirements, the exclusion of tasks, and process favor groups of staff over others. Additional research uncovers even more problems recognized by both academic administrators and faculty members.

It is accepted that some areas of faculty work are not quantifiable, including class preparation, co-curricular activities outside of the classroom, and formal and informal advising ("What's Driving Your," 2002). Additionally, the demand for faculty work between graduate and undergraduate programs may vary, but the differences may become even more pronounced due to variations in emphasizing the importance of tasks at different institutions (Green, R., 2008). These are the types of problems that led Vardi (2009) to suggest an additional set of dimensions on describing workload allocation characteristics, including time versus non-time units, formal 
versus informal activities, and democratic versus autocratic development. Even with the efforts by many to seek more reasonable comparisons between quantifiable and non-quantifiable tasks, it is the very notion of the conventional three-hour standard that has come into question by others.

As an early standard, and with a lack of an alternative, the three credit basis for workload was adequate and the transferability among class length to other pedagogies was sufficient. As the standards of teaching and learning have changed, however, so has the need for a different, less arbitrary metric of measurement (Ehrlich, 2003). This change in measurement was supported in a study by the National Center on Higher Education Research. The research suggested that a critical change in measuring faculty workload may be looming and that the shift would not be conducive to using credit-hours as a metric unless there were some significant modifications to the credit-hour system (Ehrlich, 2003). The credit-hour was acceptable for faculty activities, but the research suggested that any metric would be. At issue is the move toward student learning rather than faculty teaching, necessitating a break in conventional workload allocation. Specifically, instruction components would include workload in design, development, delivery, mentoring, and assessment (Ehrlich, 2003). Until then, the credit-hour standard remains.

Although an awkward measurement, the credit-hour does offer some validity for measuring the instructional component of workload. With research and service as the two other categories generally assigned for workload allocation, it is the credit-hour, derived from classroom teaching, which serves as the benchmark (Ehrlich, 2003). Universities do not convert credit-hours into some value of research or service, but rather assign the latter into a value for the 
former. Although all three components become part of faculty workload, a faculty member's career is most likely dependent on periodic reviews of research and service. The next section is an examination of the components for faculty workload.

\section{Components}

One of the most critical factors to faculty life is the expectation of workload. The time dedicated to workload components can have implications to faculty members' professional success or failure (Seaberg, 1998). To be effective, workload allocation processes should reflect all of the work done by faculty, including the time required to do it effectively, without favoring any single person or group (Vardi, 2009). At the same time, the academic cultures and institutional missions must remain central to planning processes. Respecting an academic culture, while at the same time managing faculty workload obligations, has been described as a balancing act of the complex and variable (Houston et al., 2006). Before the components of faculty work are identified, academic administrators must determine which standard to use, standards frequently established by those outside academe.

Elected officials are increasingly pressuring university academic administrators to make faculty members more productive and accountable. The success of academic institutions becomes dependent upon the implementation of reliable benchmarks and the evaluation of faculty work (Rosser, 2004). Although benchmarks are usually measured in terms of credithours, other terms are still used within some institutions. For example, The College of Arts and Sciences at the University of Alabama uses the term hours, whereas published guidelines for most institutions refer to contact hours or credit-hours (Ehrlich, 2003). The terminology can be 
important for interpretation. Not only do legislators sometimes use workload to dictate faculty accountability, in some instances the actual allocation of workload is established.

The pressure to recognize academic freedom and autonomy may result in conflict when legislators suggest enhancing some areas of faculty work over others. A committee established by the Ohio Board of Regents recommended guidelines for workload allocation. The guidelines established percentages of teaching versus research by university types, with institutions offering bachelor's, master's, and doctorate degrees as having a norm of 50 to 60 percent teaching. Institutions with two-year or associate degree programs were expected to maintain 80 to 90 percent of their workload as teaching (Ehrlich, 2003). After several legal challenges between faculty and academic administrators, and having reached all the way to the United States Supreme Court, the legal decision was established in favor of the legislation upon remand. Not all institutions have external mandates for workload, although there are generally accepted workload expectations, at least in the number of credit-hours for which individual faculty are responsible.

The typical expectation at high-research universities is that faculty members teach four courses, or 12 credit-hours per year (Green et al., 2008). Additionally, faculty members should publish at least twice a year. In some cases, although not the norm, faculty could be assigned as many as 12 teaching hours in a single semester ("Managing Faculty Workload," 2005). Reductions in teaching obligations are often granted in accordance with research and service demands. It is the emphasis on each of the three primary areas of faculty obligations that becomes the focal point of academic administrator and faculty reconciliation of workload allocation. 
Teaching remains a fundamental component in allocating most workloads. Whether measured in credit-hours or some other metric, workload equivalents almost always come back to the primary responsibility of teaching. In order to achieve tenure and promotion, faculty members are presumed "to have the opportunity to deliver quality teaching, conduct substantive research, and provide adequate service" (Lau, 1996, p. 96). Because teaching is not all that faculty members are expected to do, some level of flexibility exists in allocating workloads. That flexibility, however, may lead to an arbitrary expectation of work priority (Ehrlich, 2003). Emphasis among the three components may vary considerably by institutional type. As institutions increase the levels of degrees offered, so do the expectations for the prominence of scholarship in workload (Ehrlich, 2003; Green, R., 2008,). Even as research increases, it shares with teaching as the core expectations of university roles (Houston et al., 2006). By using the metric of a credit-hour for calculating faculty workloads, the academic industry has recognized the finite limit of time. Simple economics demonstrates that with limited supply of a resource, demand for that resource becomes increasingly acute.

Time for teaching responsibilities and scholarship demands often conflict. Freedenthal et al. (2008) reported both tangible and intangible resources as a factor in faculty's ability to adequately sustain workload expectations. Their research reported findings of a negative correlation between time devoted to teaching and research productivity. Further, Freedenthal et al. offered mechanisms to allow for faculty scholarship, including lighter teaching loads, external funding to offset required teaching, reductions in teaching based on prior or future productivity, and reduced workloads for tenure-track faculty. Even so, the recommendations mandate a giveand-take scenario: One component of faculty workload suffers at the expense of another. 
With the expectation that faculty engage in scholarly activity (June, 2008), universities recognize that the allocation of faculty workload needs to be designed to help faculty achieve in multiple and varied circumstances. Faculty members who desire innovation in course design may be able to do so with the approval and encouragement of academic administrators, but the competition for time to complete other expectations often works against innovation (Ehrlich, 2003). Research and publication productivity will necessarily be sacrificed if faculty members choose, or are required, to spend more time preparing for and practicing teaching ("What's Driving Your", 2002). In Durham et al. (2007) research, the assertion is confirmed that scholarly activity is constrained in workloads that include high emphasis in teaching. The research by Durham et al. (2007) contends high teaching workloads involve heavy teaching, course coordination, and university service, although service is frequently considered the third component of faculty workload. The emphasis for the division of faculty workload components is not always congruent among societal, administrative, and faculty expectations.

In 2006, Houston et al. noted Kerr's assertion:

Society hopes that university teachers will not neglect their teaching responsibilities but rewards them almost entirely for research and publications. Consequently, it is rational for university teachers to concentrate on research, even to the detriment of teaching and the expense of their students. (p. 18; emphasis in original)

Faculty members are almost always required to place that for which they are primarily evaluated, scholarship, behind teaching (Green, R., 2008). Ladd's 1979 research maintained that faculty spend more time on teaching than on scholarship, but also contends the time spent on teaching increases as faculty age. Faculty productivity is difficult to quantify when one 
considers all that is involved in class preparation, committee work, community service, and professional presentations ("What's Driving Your," 2002). With so many stakeholders affected, the need to synchronize expectations seems inevitable.

The twofold requirement facing faculty at today's universities, knowledge development and knowledge transmission, creates an increasingly demanding work environment for faculty (Houston et al., 2006). Because of the complexity of the expectations of faculty workload, a reward system needs to be defined and managed at all levels: individually, departmentally, and institutionally. The problem is, even with cooperation, the outcome of this effort may produce inconsistencies in perceptions. For example, in an ASHE-ERIC report ("What's Driving Your," 2002), teaching additional courses was seen by critics as an improvement in faculty productivity, while faculty saw it as decreased productivity via load escalation. Faculty maintained the outcome would reduce discretionary time for scholarship, but academic administrators countered that increased workloads lowered instructional costs. There is evidence that both opinions may be true and that there can be a synergistic and complementary approach to teaching and scholarship, or the approach may be antagonistic and competing (Houston et al.). The differences may profoundly affect the satisfaction and performance of an institution's faculty members.

Faculty workload complexity and variations of measurement are well documented. In its most simplistic measure, faculty workload is the number of classes and the number of students for which a faculty is responsible (Seaberg, 1998). More complex explanations of measurement pose immense problems. The fundamental differences may inhibit faculty morale, well-being, and even the productivity that workload allocation is designed to enhance (Green, R., 2008). 
Research indicates many faculty members report being overworked, but that they adapt and learn how to balance their professional obligations, negotiate workloads, and divide time between professional and personal time (Durham et al., 2007). In doing so, they also report that they become increasingly less satisfied with their profession.

\section{Job Satisfaction}

Blind spots still exist in the complex relationship among the stakeholders in workload management (Houston et al., 2006), creating a need to investigate the impact of workload stress to improve the quality of faculty job satisfaction. Examining workload management out of concern for motivating faculty in a less stressful manner is imperative, but the comparison of workload components in seeking equity often results in an incongruous outcome. Still, the need to seek an equitable balance is significant for job satisfaction (Durham et al., 2007; Vardi, 2009). Because of its impact on whether a faculty member decides to continue working in academics or not, workload allocation is crucial for faculty (Seaberg, 1998). Because of its impact on the institution, workload management is crucial for academic administrators. The reconciliation of faculty definitions of productivity with institutional resource allocation is a dilemma for higher education institutions ("What's Driving Your," 2002). The comparison between faculty productivity and faculty workload is crucial. The different goals and ideologies of faculty and academic administrators potentially provides for faculty job dissatisfaction.

Faculty productivity is an estimate of the efficiency and effectiveness of a faculty member in achieving expected professional standards, or designates how well faculty members accomplish their professional responsibilities per unit of resources invested while faculty workload refers to how much a faculty member has to do and the total set 
of activities in the formal and informal job description of a professor. (Allen, 1996, p.25) Increasing output through administrations' definition of productivity makes most faculty members feel as if they are faculty workers whose performance is measured primarily by cost savings (Massey \& Wilger, 1992). In a direct contrast between productivity and meaningful work, those faculty members whose teaching loads are heaviest, or highly productive, view their work contributions as undervalued. Likewise, faculty members who are productive in scholarship feel their colleagues have little appreciation for the time requirements of their work (Durham et al., 2007). The balance of workload as assigned or negotiated by academic administrators and the appreciation for and by faculty, even inter-collegially, is easily disrupted.

Academic administrators can merge the definitions of faculty workload and faculty productivity by not only including the natural metrics such as students in a class, number of publications, and committee membership, but also including intangibles such as teaching excellence and performance quality ("What's Driving Your," 2002). As workload models become increasingly complex, however, faculty members become increasingly dissatisfied (Vardi, 2009). The simplest measure of faculty workload continues to be based on contact hours, and the simplest measure of contact hours is the teaching component of their workload. It is also the teaching component that most external stakeholders recognize, although the overall workload requirements are more expansive and inclusive (Seaberg, 1998). Still, each of the three components is required for most faculty, with the emphasis being determined through multiple means.

Two primary means for approaching workload allocation are complementary work role expectations and symmetrical work role expectations. At institutions or departments that assign 
work roles with complementary expectations, faculty may shift their work priorities as they achieve seniority and advance in rank. Institutions with symmetrical work role practices assign all faculty members the same priority for all of the three components regardless of rank and seniority (Green, R., 2008). Problems develop with the differences between work roles and workload policies. With faculty morale hampered by the disconnect between work role and workload, faculty productivity and recruitment suffer. The conflict between work roles and work load may also account for ambiguous time priorities, resulting in reduced research and publishing (Green, R., 2008). By either practice, complementary or symmetrical assignment of work, institutions may further negatively affect faculty satisfaction.

Any unintended impact on the transparency of workload allocation processes may result in faculty dissatisfaction. It may also result in faculty resisting any work they see as less valued (Vardi, 2009). Although any type of workload allocation process may distribute work equitably, the transparency of distribution, and more importantly the need to resist widespread work overload, must remain at the forefront of the workload policy. As institutions diversify the range of expected activities faculty are to undertake, the question emerges whether all individuals need to excel in all areas of an institution's mission. As the role expectations of faculty emerge, the need to re-examine workload policy also increases. Keeping transparency and individual work profiles is critical in the re-examination. (Vardi, 2009). Additionally, both faculty and academic administrators should recognize the emerging distinct and diverse missions among universities and the natural competition for faculty as they seek satisfaction in the work they conduct.

Institutions are not immune to competition from other institutions for faculty expertise. Many institutions have developed informal norms in their workload processes to reflect those of 
competing institutions ("Managing Faculty Workload," 2005). If an institution does not provide adequate resources to maintain a scholarly culture, faculty may seek an academic position at another college or university. Resources faculty members seek include both material and intangible provisions, and in many cases the focus is on a sustainable research agenda. Freedenthal at al. (2008) classify such resources into three categories, including time, funding, and technical training and assistance. The personal desire to pursue research may change over the course of faculty careers, and the opportunity for that growth and development must exist within an institution (June, 2008). Emphasis on the progression is part of the equation for keeping faculty satisfied with their jobs. Equally important is the need to get new faculty started in a favorable work environment.

Professors new to the academic life encounter a variety of challenges and stress-inducing conditions (Durham et al., 2007). Studies show that most new professors indicate "they lead an unbalanced life, do not feel a sense of community or collegiality in their workplace, and are at the mercy of an unwieldy and vague tenure system" (Green, et al., 2008, p. 432). Among other reported concerns, being overworked consistently emerged as a response by new professors. As they improved their skills of balancing their work and negotiating workloads, pre-tenured professors reported being increasingly dissatisfied with the academic profession (Durham et al., 2007). The faculty perspective on workload and how it affects job satisfaction throughout one's career still does not negate the administrative mandate to increase resource productivity.

Accountability of resources is the primary purpose for collecting data on faculty work. Further, most of the data gathered are incorporated in analyzing costs and resource allocation decisions for the institution. The data are usually not used for addressing equity issues among 
faculty, although studies have indicated equity as a high concern by faculty (Mayes, 1998). Keeping both institutional goals and faculty satisfaction in balance may be difficult for department chairs in their roles as leaders. The ability to negotiate and manage conflict is imperative for chairs as they address faculty workloads and professional development (Lumpkin, 2004). Often it is the dissatisfaction of work assignments that leads to the development of workload models. By making the model and teaching workloads public, chairs and other academic administrators can improve faculty morale and increase accountability simultaneously. Ultimately, the responsibility for a successful role in academic work belongs to both faculty and academic administrators, usually at the chair's level (Houston et al., 2006). Even with the best effort, the result is not always one of faculty job satisfaction.

A Work Environment Survey (Houston et al., 2006) reported faculty are spending more time at work in order to meet the demands of their work. Some faculty reported working more than 10 hours beyond what they considered full-time work. The study revealed faculty attitudes of excessive workloads and inadequate value for the work they do, even with full acknowledgement of a workload allocation process. In the same study, faculty expressed "concern regarding the fairness and transparency of the workload allocation process" (Houston, et al., p.25). As a major factor in stress, increasing workload is demotivating and negatively impacts work performance. In turn, overall job satisfaction suffers (Vardi, 2009). As faculty workload demands increase, the time dedicated to each component becomes more and more valuable.

The competition for time to adequately complete heavy workload requirements can be a powerful force and loom as a barrier to productivity (Ehrlich, 2003; Freedenthal et al., 2008). 
With teaching as the component receiving the most attention from external stakeholders, faculty members are frequently at odds in finding time for research interests. Those faculty members who want to be innovative in their teaching often face administrative encouragement, but also report a lack of reward. A 1997 study found most faculty members were critical of the work environment, citing stress to balance workload as a major factor in the dissatisfaction (Houston et al., 2006). The same report also identified reward for the work as insufficient, particularly in relationship to those working in fields other than academe. Faculty members have continued to report dissatisfaction with both internal and external motivators.

Many faculty members believe intrinsic motivators play a greater role than extrinsic motivators in developing and maintaining job satisfaction and a commitment to the profession (Houston et al., 2006). Faculty self-value is supported through a structure that recognizes the human needs of faculty, and an administrative style that recognizes the psychological needs of faculty plays an important role in preserving faculty morale (Himes, 2005). Although faculty place great importance on internal motivators for faculty satisfaction, faculty tend to report on the negative effects of external factors.

Research findings report that external motivators such as salary, institutional recognition, work conditions, and promotion opportunities continue to be considered inadequate by faculty expectations (Comm \& Mathaisel, 2003; Durham et al., 2007; McGurdy \& Zegwaard, 2009). As faculty members continue in their careers, these factors contribute even more to stress and discontent. By recognizing faculty accomplishments and including them in planning and workload decisions, academic administrators may provide a more satisfactory environment for faculty (Hill, 2009; Himes, 2005). Additionally, an environment of flexibility and autonomy 
increases faculty satisfaction and meets the expectations most have when they choose the profession (Houston et al., 2006). External motivators and rewards for faculty are numerous, and none stands alone. However, one very important reward frequently rises to the top of the list.

Frequently, salary is beyond the control of academic administrators most close to understanding faculty workloads. In many instances, faculty salary is set by those most concerned with only the teaching component of faculty workloads - legislators. With such a large role in determining job satisfaction, researchers have tried to determine whether there is a correlation between faculty salaries and job satisfaction. Results indicate that faculty dissatisfaction is immune to institutional resources. Faculty with higher salaries from institutions with large endowments are just as likely to report dissatisfaction as are faculty with lower salaries from small institutions (Himes, 2005).

It is clear that job satisfaction for faculty members is affected by many variables. Many of those variables are directly traceable to faculty workload allocation. As indicated by Comm and Mathaisel (2003), employee job satisfaction and customer satisfaction are equally important for the overall performance of the organization. The roles of academic administrators and faculty in the workload allocation process can be cooperative or confrontational, and the results can have an impact on all stakeholders, from the student to the most senior academic administrator, and from the public to the government.

\section{Comparative Study}

Vardi's 2009 research on different types of workload allocation and the effect of each on academic satisfaction was thorough and conclusive for the population under study. Using economic factors, or a comparison of resource supply to demand, as a factor in placing value in 
the research, Vardi recognized the need to examine how changing workload allocation demands affect both faculty and academic administrators. Her analysis examined positive and negative impacts of workload allocation models from the perspective of both faculty and academic administrators. In addition to her focus on satisfaction, Vardi's research examined the equity of workload distribution, different models for measuring the components of workload, and the management of workload allocation. The methods used to gather information for Vardi's research were semi-structured interviews and focus groups. Vardi's populations were academic administrators and faculty from a large Australian University. Her sample included 50 administrative department heads and 22 faculty members. Vardi’s research provides a foundation for expansion for similar research in the United States. With the addition of a survey instrument, a different population and a larger sample, and a defined academic discipline, this study offers greater understanding to the process of workload allocation and its' effect on academic administrators and faculty members. 


\section{Chapter Three: Methods of the Study}

Chapter Three presents a general overview of the research set in context, a description of the population and sample, a description of the instrument creation, procedures toward research, and the data analysis methods. Each of the following sections aid in understanding the methodology and in duplicating the research in future endeavors.

\section{Research in Context of Workload Allocation Processes}

Through a quantitative research design, this study addressed the question of whether there is a statistically significant difference in faculty and academic administrator perceptions of workload allocation. Data were gathered via electronic survey techniques through a 35 item instrument developed to measure perceptions of five domains on a Likert-type scale. The five domains are as follows:

Domain 1: Perceptions of Workload Allocation Process Value;

Domain 2: Perceptions of Workload Allocation Process Equity and Transparency;

Domain 3: Perceptions of Workload Allocation Process Fairness;

Domain 4: Perceptions of Workload Allocation Process Components; and

Domain 5: Perceptions of Workload Allocation Process Effects on Job Satisfaction.

In order to conduct a valid comparison, items were sorted for internal consistency within each domain. The instrument was administered to two groups, identified as full-time faculty members or academic administrators, from a population defined as faculty and academic administrators from colleges of education offering doctorate degrees at 19 RU/H Research Universities (high research activity) in the southeast United States as classified by the Carnegie Classification System (Carnegie Foundation for the Advancement of Teaching, n.d.). These 
institutions are defined as doctorate-granting universities that awarded at least 20 research doctoral degrees during the update year (excluding doctoral-level degrees that qualify recipients for entry into professional practice, such as the JD, MD, PharmD, DPT, etc.) and excluding Special Focus Institutions and Tribal Colleges.

\section{Research Population and Sample}

As described previously, the purpose of this study is to focus on the creation of an instrument to measure faculty and academic administrator perceptions of the workload allocation process. Therefore, it is necessary to choose a sample that includes institutions in which each of the components of a workload allocation process is present. The Carnegie Classification System category of high research activity was chosen because of the equal approach to both research and teaching, and because faculty may vary in the emphasis among all three components. Further, no one has actually determined which component is most valuable, therefore the perceptions of both faculty and academic administrators are important to equalize faculty work force productivity across distinguishable units as defined by the institution.

The populations for this study are faculty members and academic administrators from colleges of education offering doctorate degrees at 19 RU/H Research Universities (high research activity) (see Table 1) in the southeast United States as classified by the Carnegie Classification System of the Carnegie Foundation for the Advancement of Teaching (http://classifications.carnegiefoundation.org). A cluster sample was selected from both faculty and academic administrators representing each of the institutions of the population. Cluster samples maintain the probability sampling method desired in quantitative studies while ensuring each of the institutions was represented (Burns \& Bush, 2008). 
Table 1

Education Doctorate-Granting Universities with High Research Activity in Southeast United States

Auburn University Main Campus

Clemson University

Florida Atlantic University

Florida International University

George Mason University

Jackson State University

Louisiana Tech University

Nova Southeastern University

Old Dominion University

The University of Alabama

University of Louisiana at Lafayette

University of Memphis

University of Mississippi Main Campus

University of New Orleans

University of North Carolina at Greensboro

University of South Alabama

University of Southern Mississippi

Wake Forest University

West Virginia University 


\section{Instrument Creation}

The survey instrument was created to measure the faculty and academic administrator perceptions of the workload allocation process. After a review of secondary data, the author identified five primary areas of interest for the comparison of faculty and academic administrator perceptions and named the areas, or domains, descriptively. After the identifying the primary areas, the author again reviewed the secondary sources and placed statements from those sources into one of each of the five domains. Because the compilation of more than 200 items from the secondary data was redundant, lengthy, and verbose, items were identified by key areas and combined into a manageable survey instrument in order to avoid respondent fatigue and frustration. Although a more lengthy questionnaire may be considered to be more reliable than a short one (Suskie, 1996), the survey instrument was created to include internal consistency in its 35 items.

As Suskie (1996) advocates, the survey instrument began with items designed to intrigue respondents in order to increase participation and response rate. Domain items were developed through a review of secondary data from which key themes were identified. Those themes became the domains into which more than 200 individual items were placed. In developing the instrument, the primary focus was on translating the information goals into questions, or items, included in the instrument (Sudman \& Blair, 1998). With more than 200 initial items, the focus of the instrument development included topics of reliability, validity, ordering of items, wording of items, software support for analyzing results, and subject matter to be included in items (Burns \& Bush, 2008; Suskie, 1996). Redundant items were combined into items and wording for each resultant item was arranged as a statement for a Likert-type scaled response. This type 
of survey allows respondents to choose their level of agreement with the statement along a fivepoint scale between strongly agree and strongly disagree. To increase construct validity, some questions were worded in the negative, with particular attention drawn to the negative descriptor through use of capitalization (Suskie, 1996). Minimal demographic questions are included at the end of the survey instrument for use in comparative analysis. The demographic questions include respondents' status as a faculty member or administrative position and the number of years as a faculty member or academic administrator.

Once developed from the domain items (Appendix A), the instrument was reviewed by a panel to test for (a) content validity, (b) internal consistency, (c) question wording, and (d) the instrument format. Additionally, comments from the panel members who reviewed the instrument were considered for construct validity, design improvement, and instrument revision (Creswell, 2003). After reviews were completed, the instrument domains and items were revised and again reviewed.

In the final review, the instrument was subjected to panel members' opinion for construct validity by asking under which domain the respondent would place each of the 40 items. Items were listed without an associated domain, and experts were asked to place each item into the domain they considered most applicable for the item. Panel members placed $88 \%$ of the items under the domains to which they had originally been associated. Items that that were inconsistently placed were removed from the original instrument. The resultant instrument (Appendix B) has 35 items divided among five domains, with domains ranging from five to nine items each. 


\section{Procedure}

The researcher compiled a list of electronic mailing addresses of 320 faculty and 60 academic administrators at 19 High Research Universities of the Southeast Region through institutional directories. Before being administered, the study was reviewed for exempt status by the West Virginia University Institutional Review Board (IRB) for the Protection of Human Subjects and no survey was distributed until the study had been approved. The instrument was administered electronically through Qualtrics Software. Participants were assured of confidentiality through IRB training and Qualtrics Software identity protection settings, distinguishing only whether a survey had been completed and returned from the email address. Accompanying the survey was a request to participate in the survey, including an explanation of the purpose of the study and an assurance of confidentiality (Appendix C). After ten days had passed from the initial distribution of the instrument, a reminder notice (Appendix D) was sent through Qualtrics Software's automatic response function to participants who had not yet responded. A second reminder (Appendix E) was sent two weeks later to participants who still had not completed the survey. After another two weeks had passed, a third reminder (Appendix F) was sent to those who had not yet responded. A final reminder (Appendix G) was sent the morning of the survey's termination, after which the data from the completed surveys were analyzed.

\section{Analysis}

Participant responses were organized in a nine-column grid. Each variable occupied a separate column, identified by a label for the variable. Variable labels for the grid columns are Participant, Academic administrator or Faculty, Institution, Domain 1, Domain 2, Domain 3, 
Domain 4, Domain 5, and Composite Mean Score. Descriptions of the variable labels and corresponding allowable values are contained in Table 2.

Data were entered in the grid based on each participant's response to the instrument. Each participant was assigned a sequential number beginning with 001 and ending with the total number of participants $(\mathrm{N}=380)$. Academic administrators were assigned a nominal value of 1 , faculty a nominal value of 2 . The institution from which a participant responded was assigned a nominal value of 1 to 19 based on the 19 institutions in the regional Carnegie Classification. Domains 1 through 5 include values based on the composite sum of the participants' responses to items within the domain. For example, Domain 1 contains seven items, each with possible responses between 1 and five, inclusive. Therefore, Domain 1 includes potential values of 7-35, Domain 2 includes potential values of 5-25, Domain 3 includes potential values of 8-40, Domain 4 includes potential values of 6-30, and Domain 5 includes potential values of 9-45. The composite mean score was calculated as the sum of all domain scores for the participant divided by five, the number of domains. With 35 items in the instrument and with responses ranging from $1-5$ for each item, the range for the sum is $35-175\left(1 * 35\right.$ to $\left.5^{*} 35\right)$. From the data entered into the grid, t-tests were conducted to compare academic administrator and faculty values.

A total of $41 \mathrm{t}$-tests were performed, one for each of the five domains, one for the composite mean score, and one for each of the 35 items. The t-tests measure the statistical significance between academic administrators and faculty perceptions as indicated from responses to the instrument. For each of the domains and for the composite, a mean score was calculated for both academic administrators and faculty from the values entered in the 
Table 2

Variables, Label Descriptions, and Value Codes

Variable Label

\begin{tabular}{|c|c|c|c|c|c|c|c|c|}
\hline$\underline{\text { Participant }}$ & $\begin{array}{l}\text { Administrator } \\
\text { or Faculty }\end{array}$ & Institution & Domain 1 & Domain 2 & Domain 3 & Domain 4 & Domain 5 & $\begin{array}{l}\text { Composite } \\
\text { Mean Score }\end{array}$ \\
\hline \multicolumn{9}{|c|}{$\underline{\text { Label Description }}$} \\
\hline $\begin{array}{l}\text { Identified } \\
\text { only by } \\
\text { sequential } \\
\text { number }\end{array}$ & $\begin{array}{l}\text { Respondent } \\
\text { identified as } \\
\text { Administrator } \\
\text { or Faculty }\end{array}$ & $\begin{array}{l}\text { Respondent } \\
\text { institution of } \\
\text { employment }\end{array}$ & $\begin{array}{l}\text { Sum of } \\
\text { respondent } \\
\text { Domain } 1 \\
\text { scores }\end{array}$ & $\begin{array}{l}\text { Sum of } \\
\text { respondent } \\
\text { Domain } 2 \\
\text { scores }\end{array}$ & $\begin{array}{l}\text { Sum of } \\
\text { respondent } \\
\text { Domain } 3 \\
\text { scores }\end{array}$ & $\begin{array}{l}\text { Sum of } \\
\text { respondent } \\
\text { Domain } 4 \\
\text { scores }\end{array}$ & $\begin{array}{l}\text { Sum of } \\
\text { respondent } \\
\text { Domain } 5 \\
\text { scores }\end{array}$ & $\begin{array}{l}\text { Mean value } \\
\text { of respondent } \\
\text { sum score of } \\
\text { all domains }\end{array}$ \\
\hline \multicolumn{9}{|c|}{$\underline{\text { Value Codes }}$} \\
\hline $001-380$ & 1,2 & $1-19$ & $7-35$ & $5-25$ & $8-40$ & $6-30$ & $9-45$ & $35-175$ \\
\hline
\end{tabular}


corresponding column in the grid. For example, a mean score for Domain 1 was calculated from all academic administrators as designated in column 2. Likewise, a mean score for Domain 1 was calculated for Faculty as designated from column 2. The outcomes of those two mean calculated scores were subjected to a t-test for Domain 1.

There are four basic assumptions of a t-test; (a) homogeneity, (b) independence, (c) normality, and (d) scale of measurement. Homogeneity assumes that the group sample sizes are equal and that they have equal variances. Independence assumes that the comparative groups are mutually exclusive, meaning respondents do not belong in both groups. The assumption of normality is that the two groups' measurement is normally distributed. The scale of measurement in this study is the same for both groups, ordinal, for each of the five domains. The composite mean score scale of measurement is interval.

The null hypothesis asserted that the difference in the population parameters is less than $5 \%(0.05)$ as measured by the sample means, or that there is no significant difference between faculty and academic administrators' perceptions of workload allocation processes. The alternative hypothesis was that that the difference in the population parameter is $5 \%$ or greater $(0.05+)$ as measured by the sample means, or that there is a significant difference between faculty and academic administrators' perceptions of workload allocation processes.

Failure to reject the null hypothesis, or a finding that there is no significant difference from the sample when in reality there is a difference in the population, is known as a Type II error. This condition can be avoided through statistical power with three pieces of information available: (a) effect size, (b) sample size, and (c) significance level of the study. Of the three, effect size will not be known by the researcher and must therefore be determined. 


\section{Method Summary}

Through the use of electronic survey techniques, this study measured the perceptions from two different groups, faculty members and academic administrators, from 19 high research universities in the southeast United States. Respondents representing samples from both populations completed a 35 item instrument developed specifically for the research question: Is there a significant difference between faculty and academic administrator perceptions of the workload allocation processes? Survey responses underwent statistical analysis through the use of a t-test for differences among faculty and academic administrator perceptions of the five domains and the composite mean of the domains. 


\section{Chapter Four: Analysis of Survey Results}

Chapter Four is an analysis of data collected from academic administrators' and faculty members' responses to perceptions of the workload allocation process. Through statistical analysis, the goal of this chapter is to answer the five research questions of the study. The first section summarizes the response rates and respondent demographics. The second section of the chapter is an analysis of survey responses by domain and composite mean scores, comparing the mean score of each group - academic administrators and faculty members. The third section is an analysis of survey responses by individual survey items, again comparing academic administrator and faculty member mean scores.

\section{Survey Response Rates and Participant Demographics}

The sample for this study included 380 recipients, including 320 faculty members and 60 academic administrators. Of the 182 total respondents, $N=158$ completed all or most of the survey, yielding a $41.6 \%$ response rate. Academic administrators, $N=36$, had a $60 \%$ response rate by completing all or most of the survey. Faculty members, $N=122$, had a $38.1 \%$ response rate by completing all or most of the survey. Faculty members identified themselves as tenured, $57 \%, N=69$; tenure track, $25 \%, N=31$; or limited term contract, $18 \%, N=22$.

When asked for the years of service faculty members have at their current institution, $N=37$ responded $1-5$ years, $N=33$ responded $6-10$ years, $N=28$ responded $11-15$ years, $N=12$ responded 16-20, and $N=12$ responded more than 20 years. When asked for the years of service academic administrators have at their current institution, $N=11$ responded $1-5$ years, $N=11$ responded 6-10 years, $N=5$ responded $11-15$ years, $N=3$ responded $16-20$ years, and $N=6$ responded more than 20 years (see Table 3). 
Table 3

Institutional Years of Service

\begin{tabular}{lcc}
\hline Institutional Years of Service & Faculty Members & Academic administrators \\
\hline $1-5$ & $30 \%$ & $31 \%$ \\
$6-10$ & $27 \%$ & $31 \%$ \\
$11-15$ & $23 \%$ & $14 \%$ \\
$16-20$ & $10 \%$ & $8 \%$ \\
$>20$ & $10 \%$ & $16 \%$ \\
\hline
\end{tabular}

\section{Statistical Analysis by Domain and Composite Mean Score}

Domain 1: Perceptions of workload allocation process value.

An analysis of respondents' scores indicated no statistically significant difference between the academic administrators and faculty members for Domain 1. Domain 1 contains a cluster of seven items (see Table 4). The results of this particular domain answer Research Question 1: Is there a difference in how faculty and academic administrators perceive the value of the workload allocation process?

The Domain 1 possible score range was 7 to 35 . Actual ranges for Domain 1 were 16 to 26 for academic administrators, $N=36$, and 8 to 29 for faculty members, $N=122$. A respondent whose level of agreement for each item was at the lowest level would have a score of 7, whereas a respondent whose level of agreement for each item was at the highest level would have a score of 35 . 
Table 4

Items Included in Perceptions of Workload Allocation Process Value

Item

The development of the workload allocation model at this institution includes all stakeholders. There is an imbalance between faculty desires and institutional needs at this institution.

The publication of teaching workloads results in greater awareness of others' responsibilities at this institution.

Increases in faculty workload contribute to lower instructional costs at this institution.

Workload allocation models are essential to the success of this institution.

The workload norms at this institution were developed due to competition for faculty from other institutions.

The primary purpose of the workload policy at this institution is to accommodate the present and future needs including its continuous accreditation and improvement mandates.

The Domain 1 mean score for all respondents was 21.19. Academic administrators, $N=36$, had a mean score of 21.31 and faculty members, $N=122$, mean score was 21.16 (see Table 5). A t-test was computed and yielded $t=.052, d f=156$, and $p=.647(p>.05)$ (see Table 6). The null hypothesis is not rejected; there is no significant difference in the Domain 1 mean scores of the two groups.

Table 5

Mean Scores for Perceptions of Workload Allocation Process Value

\begin{tabular}{lcccc}
\hline \multicolumn{1}{c}{ Group } & $N$ & $M$ & $S D$ & $S E M$ \\
\hline $\begin{array}{l}\text { Academic } \\
\text { administrators }\end{array}$ & 36 & 21.31 & 2.60 & .434 \\
Faculty & 122 & 21.16 & 3.43 & .310 \\
\hline
\end{tabular}


Table 6

t-test for Perceptions of Workload Allocation Process Value

\begin{tabular}{lcccc}
\hline \multicolumn{1}{c}{ Group } & $t$ & $d f$ & $p$ & $\begin{array}{c}\text { Mean } \\
\text { Difference }\end{array}$ \\
\hline $\begin{array}{l}\text { Academic } \\
\text { administrators } \\
\text { Vs. }\end{array}$ & .052 & 156 & .647 & .150 \\
Faculty & & & & \\
\hline
\end{tabular}

\section{Domain 2: Perceptions of workload allocation process equity and transparency.}

An analysis of respondents' scores indicated a statistically significant difference between the academic administrators and faculty members for Domain 2. Domain 2 contains a cluster of five items (see Table 7). The results of this particular domain answer Research Question 2: Is there a difference in perception between how academic administrators and faculty perceive the equity and transparency of the workload allocation process?

Table 7

Items Included in Perceptions of Workload Allocation Process Equity and Transparency

\section{Item}

The criteria used for tenure and promotion at my university are too broad.

Faculty members have a clear understanding of how academic administrators determine faculty workload.

Data on workload allocation at this institution is gathered to address equity issues. The workload allocation structure at this institution is transparent enough to let me know that workload demands are equitable.

The workload allocation process in my department is transparent and equitable. 
The Domain 2 possible score range was 5 to 25 . Actual ranges for Domain 2 were 8 to 22 for academic administrators, $N=36$, and 6 to 19 for faculty members, $N=122$. A respondent whose level of agreement for each item was at the lowest level would have a score of 5, whereas a respondent whose level of agreement for each item was at the highest level would have a score of 25 .

The Domain 2 mean score for all respondents was 12.66. Academic administrators, $N=36$, had a mean score of 14.61 and faculty members, $N=122$, mean score was 12.08 (see Table 8). A t-test was computed and yielded $t=.052, d f=156$, and $\mathrm{p}=.001(p<.05)$ (see Table 9). The null hypothesis is rejected; there is a significant difference in the Domain 2 mean scores of the two groups.

Table 8

Mean Scores for Perceptions of Workload Allocation Process Equity and Transparency

\begin{tabular}{lcccc}
\hline \multicolumn{1}{c}{ Group } & $N$ & $M$ & $S D$ & $S E M$ \\
\hline $\begin{array}{l}\text { Academic } \\
\text { administrators }\end{array}$ & 36 & 14.61 & 3.52 & .514 \\
Faculty & 122 & 12.08 & 3.02 & .274 \\
\hline
\end{tabular}

Table 9

t-test for Perceptions of Workload Allocation Process Equity and Transparency

\begin{tabular}{lcccc}
\hline \multicolumn{1}{c}{ Group } & $t$ & $d f$ & $p$ & Mean Difference \\
\hline $\begin{array}{l}\text { Academic } \\
\text { administrators }\end{array}$ & & & & \\
vs. & .052 & 156 & $\mathbf{. 0 0 1 *}$ & 2.529 \\
Faculty & & & & \\
\hline
\end{tabular}

$*_{p}<.05$ 


\section{Domain 3: Perceptions of workload allocation process fairness.}

An analysis of respondents' scores indicated no statistically significant difference between the academic administrators and faculty members for Domain 3. Domain 3 contains a cluster of eight items (see Table 10). The results of this particular domain answer Research Question 3: Do academic administrators and faculty perceive the fairness of the workload allocation process the same?

Table 10

Items Included in Perceptions of Workload Allocation Process Fairness

\section{Item}

The workload allocation model at this institution is fair.

My workload plan does NOT reflect the number of tasks I actually do at my university. There must be a differential in faculty workloads at this institution for fairness to occur. Preferential treatment in workload is given to some faculty members at this institution. It is fair to use credit-hours as a comparative metric for research and service.

The workload allocation model favors some faculty over others within my department. Faculty members at this institution are fairly compensated for their contributions in all areas of their workload.

Workload allocation models at this institution do NOT accurately reflect the true time it takes to complete tasks.

The Domain 3 possible score range was 8 to 40 . Actual ranges for Domain 3 were 20 to 34 for academic administrators, $N=36$, and 10 to 33 for faculty members, $N=122$. A respondent whose level of agreement for each item was at the lowest level would have a score of 8 , whereas a respondent whose level of agreement for each item was at the highest level would have a score of 40 . 
The Domain 3 mean score for all respondents was 26.38. Academic administrators $\mathrm{N}=36$, had a mean score of 26.50 and faculty members, $N=122$, mean score was 26.34 (see Table 11). A t-test was computed and yielded $t=.052, d f=156$, and $p=.750(p>.05)$ (see Table 12). The null hypothesis is not rejected; there is no significant difference in the Domain 3 mean scores of the two groups.

Table 11

Mean Scores for Perceptions of Workload Allocation Process Fairness

\begin{tabular}{lcccc}
\hline \multicolumn{1}{c}{ Group } & $N$ & $M$ & $S D$ & $S E M$ \\
\hline $\begin{array}{l}\text { Academic } \\
\text { administrators }\end{array}$ & 36 & 26.50 & 3.09 & .514 \\
Faculty & 122 & 26.34 & 3.55 & .321 \\
\hline
\end{tabular}

Table 12

t-test for Perceptions of Workload Allocation Process Fairness

\begin{tabular}{lcccc}
\hline \multicolumn{1}{c}{ Group } & $t$ & $d f$ & $p$ & Mean Difference \\
\hline $\begin{array}{l}\text { Academic } \\
\text { administrators }\end{array}$ & & & & \\
Vs. & .052 & 156 & .750 & .156 \\
Faculty & & & & \\
\hline
\end{tabular}

\section{Domain 4: Perceptions of workload allocation process components.}

An analysis of respondents' scores indicated no statistically significant difference between the academic administrators and faculty members for Domain 4 . Domain 4 contains a cluster of six items (see Table 13). The results of this particular domain answer Research 
Question 4: Do academic administrators and faculty perceive the value of the components of the workload allocation similarly?

Table 13

Items Included in Perceptions of Workload Allocation Process Components

Item

By requiring faculty to spend more time in the classroom teaching larger class sizes, this institution sacrifices some portion of research and publication productivity.

Faculty are rewarded more for research and publications than for teaching at this institution.

Faculty at this institution are expected to place teaching obligations before scholarship and service.

The comparison of teaching credit-hours to the amount of research and service faculty conduct is arbitrary at this institution.

At this institution, scholarship teaching and service are rewarded equally.

Faculty members at this institution are expected to be productive in three primary areas

(teaching, research, and service) whereas they are evaluated by their teaching load alone by those outside the institution.

The Domain 4 possible score range was 6 to 30. Actual ranges for Domain 4 were 11 to 23 for academic administrators, $N=36$, and 10 to 25 for faculty members, $N=122$. A respondent whose level of agreement for each item was at the lowest level would have a score of 6 , whereas a respondent whose level of agreement for each item was at the highest level would have a score of 30 .

The Domain 4 mean score for all respondents was 18.12. Academic administrators, $N=36$, had a mean score of 17.78 and faculty members, $N=122$, mean score was 18.22 (see Table 14). A t-test was computed and yielded $t=.052, d f=156$, and $p=.237$ ( $p>.05$ ) (see Table 15). The null hypothesis is not rejected; there is no significant difference in the Domain 4 mean scores of the two groups. 
Table 14

Mean Scores for Perceptions of Workload Allocation Process Components

\begin{tabular}{lcccc}
\hline \multicolumn{1}{c}{ Group } & $N$ & $M$ & $S D$ & $S E M$ \\
\hline Academic & & & & .491 \\
administrators & 36 & 17.78 & 2.95 & .269 \\
Faculty & 122 & 18.22 & 2.97 & \\
\hline
\end{tabular}

Table 15

t-test for Perceptions of Workload Allocation Process Components

\begin{tabular}{lcccc}
\hline \multicolumn{1}{c}{ Group } & $t$ & $d f$ & $p$ & Mean Difference \\
\hline $\begin{array}{l}\text { Academic } \\
\text { administrators }\end{array}$ & & & & \\
vs. & .052 & 156 & .237 & .444 \\
Faculty & & & & \\
\hline
\end{tabular}

Domain 5: Perceptions of workload allocation process effects on job satisfaction.

An analysis of respondents' scores indicated no statistically significant difference between the academic administrators and faculty members for Domain 5. Domain 5 contains a cluster of nine items (see Table 16). The results of this particular domain answer Research Question: Do academic administrators and faculty perceive the relationship between workload and job satisfaction in the same way?

The Domain 5 possible score range was 9 to 45 . Actual ranges for Domain 5 were 22 to 38 for academic administrators, $N=36$, and 23 to 38 for faculty members, $N=122$. A respondent whose level of agreement for each item was at the lowest level would have a score of 9, whereas 
a respondent whose level of agreement for each item was at the highest level would have a score of 45 .

Table 16

Items Included in Perceptions of Workload Allocation Process Effects on Job Satisfaction

Item

The faculty members at this institution work in an increasingly demanding environment.

Workload differences at this institution cause problems among faculty members.

Faculty members at this institution feel the time needed to invest in research is underappreciated.

Faculty members at this institution are dissatisfied when comparing their workload and salary to those outside academe.

The administration at this institution adequately values faculty productivity.

Over time, faculty at this institution become less content with university support of salary as it compares to workloads.

Faculty morale at this institution has improved because of the consistent application of faculty workloads.

The publication of teaching workloads results in improved faculty morale at this institution. Faculty at this institution feel pressured to undertake tasks that are not part of their workload plan.

The Domain 5 mean score for all respondents was 30.53. Academic administrators, $N=36$, had a mean score of 30.50 and faculty members, $N=122$, mean score was 30.53 (see Table 17). A t-test was computed and yielded $t=.052, d f=156$, and $p=.960$ ( $p>.05)$ (see Table 18). The null hypothesis is not rejected; there is no significant difference in the Domain 5 mean scores of the two groups. 
Table 17

Mean Scores for Perceptions of Workload Allocation Process Effects on Job Satisfaction

\begin{tabular}{lcccc}
\hline \multicolumn{1}{c}{ Group } & $N$ & $M$ & $S D$ & $S E M$ \\
\hline $\begin{array}{l}\text { Academic } \\
\text { administrators }\end{array}$ & 36 & 30.50 & 3.85 & .641 \\
Faculty & 122 & 30.53 & 3.69 & .334 \\
\hline
\end{tabular}

Table 18

t-test for Perceptions of Workload Allocation Process Effects on Job Satisfaction

\begin{tabular}{lcccc}
\hline \multicolumn{1}{c}{ Group } & $t$ & $d f$ & $p$ & Mean Difference \\
\hline $\begin{array}{l}\text { Academic } \\
\text { administrators }\end{array}$ & & & & \\
vs. & .052 & 156 & .960 & .033 \\
Faculty & & & & \\
\end{tabular}

\section{Composite of all domain mean scores.}

An analysis of the composite of all five domain scores indicated no statistically significant difference between the academic administrators and faculty members. The possible range for the composite mean score was 35 to 175. Actual ranges for the composite mean score were 99 to 134 for academic administrators, $N=36$, and 80 to 130 for faculty members, $N=122$. A respondent whose level of agreement was at the lowest level for each item in all domains would have a score of 35, whereas a respondent whose level of agreement was at the highest level for each item in all domains would have a score of 175. 
The composite mean score for all respondents was 108.87. Academic administrators, $N=36$, had a composite mean score of 110.69 and faculty members, $N=122$, composite mean score was 108.34 (see Table 19). A t-test was computed and yielded $t=.052, d f=156$, and $p=.190(p>.05)$ (see Table 20). The null hypothesis is not rejected; there is no significant difference in the composite mean scores of the two groups.

Table 19

Composite Mean Scores for Perceptions of Workload Allocation Process

\begin{tabular}{lcccc}
\hline \multicolumn{1}{c}{ Group } & $N$ & $M$ & $S D$ & $S E M$ \\
\hline $\begin{array}{l}\text { Academic } \\
\text { administrators }\end{array}$ & 36 & 110.69 & 8.16 & .334 \\
Faculty & 122 & 108.34 & 10.50 & .957 \\
\hline
\end{tabular}

Table 20

t-test for Composite Mean Scores

\begin{tabular}{lcccc}
\hline \multicolumn{1}{c}{ Group } & $t$ & $d f$ & $p$ & Mean Difference \\
\hline $\begin{array}{l}\text { Academic } \\
\text { administrators }\end{array}$ & & & & \\
vs. & .052 & 156 & .190 & 2.358 \\
Faculty & & & & \\
\hline
\end{tabular}

\section{Statistical Analysis by Item}

Participants responded with their level of agreement on each of the 35 statements. The Likert-type scale included choices ranging from strongly disagree to strongly agree, 1 to 5 respectively. 


\section{Survey item one.}

The first item on the survey instrument read: The development of the workload allocation model at this institution includes all stakeholders. Scoring for this item was reversed. A score of 1 indicated agreement with the statement and 5 indicated disagreement. Academic administrators, $N=36$, had a mean score of 2.72 and faculty members, $N=120$, mean score was 3.39 (see Table 21). A t-test was computed and yielded $t=.052, d f=156$, and $p=.002(p<.05)$ (see Table 22). The null hypothesis is therefore rejected; there is a significant difference in the mean scores of the two groups.

Table 21

Mean Scores for Item 1

\begin{tabular}{lcccc}
\hline \multicolumn{1}{c}{ Group } & $N$ & $M$ & $S D$ & $S E M$ \\
\hline $\begin{array}{l}\text { Academic } \\
\text { administrators }\end{array}$ & 36 & 2.72 & 1.0701 & .184 \\
Faculty & 120 & 3.39 & 1.0512 & .098 \\
\hline
\end{tabular}

Table 22

t-test for Item 1

\begin{tabular}{lcccc}
\hline \multicolumn{1}{c}{ Group } & $t$ & $d f$ & $p$ & Mean Difference \\
\hline $\begin{array}{l}\text { Academic } \\
\text { administrators }\end{array}$ & & & & \\
vs. & .052 & 154 & $\mathbf{. 0 0 2 *}$ & .669 \\
Faculty & & & &
\end{tabular}

$*_{p}<.05$ 


\section{Survey item two.}

The second item on the survey instrument read: There is an imbalance between faculty desires and institutional needs at this institution. Academic administrators, $N=36$, had a mean score of 2.58 and faculty members, $N=120$, mean score was 2.47 . A t-test was computed and yielded $t=.052, d f=154$, and $p=.557(p>.05)$. The null hypothesis is not rejected; there is no significant difference in the mean scores of the two groups.

\section{Survey item three.}

The third item on the survey instrument read: The publication of teaching workloads results in greater awareness of others' responsibilities at this institution. Academic administrators, $N=36$, had a mean score of 3.39 and faculty members, $N=119$, mean score was 3.08. A t-test was computed and yielded $t=.052, d f=153$, and $p=.114(p>.05)$. The null hypothesis is not rejected; there is no significant difference in the mean scores of the two groups.

\section{Survey item four.}

The fourth item on the survey instrument read: Increases in faculty workload contribute to lower instructional costs at this institution. Academic administrators, $N=36$, had a mean score of 3.22 and faculty members, $N=121$, mean score was 3.21. A t-test was computed and yielded $t=.052, d f=155$, and $p=.939(p>.05)$. The null hypothesis is not rejected; there is no significant difference in the mean scores of the two groups.

\section{Survey item five.}

The fifth item on the survey instrument read: Workload allocation models are essential to the success of this institution. Academic administrators, $N=36$, had a mean score of 3.50 and faculty members, $N=119$, mean score was 3.69 . A t-test was computed and yielded $t=.052, d f$ 
$=153$, and $p=.282(p>.05)$. The null hypothesis is not rejected; there is no significant difference in the mean scores of the two groups.

\section{Survey item six.}

The sixth item on the survey instrument read: The workload norms at this institution were developed due to competition for faculty from other institutions. Academic administrators, $N=36$, had a mean score of 2.47 and faculty members, $N=121$, mean score was 2.50 . A t-test was computed and yielded $t=.052, d f=155$, and $p=.870(p>.05)$. The null hypothesis is not rejected; there is no significant difference in the mean scores of the two groups.

\section{Survey item seven.}

The seventh item on the survey instrument read: The primary purpose of the workload policy at this institution is to accommodate the present and future needs including its continuous accreditation and improvement. Academic administrators, $N=36$, had a mean score of 3.42 and faculty members, $N=120$, mean score was 3.18. A t-test was computed and yielded $t=.052, d f$ $=154$, and $p=.179(p>.05)$. The null hypothesis is not rejected; there is no significant difference in the mean scores of the two groups.

\section{Survey item eight.}

The eighth item on the survey instrument read: The criteria used for tenure and promotion at my institution are too broad. Academic administrators, $N=36$, had a mean score of 2.44 and faculty members, $N=122$, mean score was 2.84 (see Table 23 ). A t-test was computed and yielded $t=.052, d f=156$, and $p=.048(p<.05)$ (see Table 24$)$. The null hypothesis is therefore rejected; there is a significant difference in the mean scores of the two groups. 
Table 23

Mean Scores for Item 8

\begin{tabular}{lcccc}
\hline \multicolumn{1}{c}{ Group } & $N$ & $M$ & $S D$ & SEM \\
\hline $\begin{array}{l}\text { Academic } \\
\text { administrators }\end{array}$ & 36 & 2.44 & .9844 & .235 \\
Faculty & 122 & 2.84 & 1.1875 & .089 \\
\hline
\end{tabular}

Table 24

t-test for Item 8

\begin{tabular}{lcccc}
\hline \multicolumn{1}{c}{ Group } & $t$ & $d f$ & $p$ & Mean Difference \\
\hline $\begin{array}{l}\text { Academic } \\
\text { administrators }\end{array}$ & & & & \\
Vs. & .052 & 156 & $\mathbf{. 0 4 8 *}$ & .400 \\
Faculty & & & &
\end{tabular}

$* p<.05$

\section{Survey item nine.}

The ninth item on the survey instrument read: Faculty have a clear understanding of how academic administrators determine faculty workload. Academic administrators, $N=36$, had a mean score of 3.25 and faculty members, $N=121$, mean score was 2.29 (see Table 25 ). A t-test was computed and yielded $t=.052, d f=155$, and $p=.000(p<.05)$ (see Table 26). The null hypothesis is therefore rejected; there is a significant difference in the mean scores of the two groups. 
Table 25

Mean Scores for Item 9

\begin{tabular}{lcccc}
\hline \multicolumn{1}{c}{ Group } & $N$ & $M$ & $S D$ & $S E M$ \\
\hline $\begin{array}{l}\text { Academic } \\
\text { administrators }\end{array}$ & 36 & 3.25 & 1.1873 & .235 \\
Faculty & 121 & 2.29 & .9658 & .108 \\
\hline
\end{tabular}

Table 26

t-test for Item 9

\begin{tabular}{lcccc}
\hline \multicolumn{1}{c}{ Group } & $t$ & $d f$ & $p$ & Mean Difference \\
\hline $\begin{array}{l}\text { Academic } \\
\text { administrators }\end{array}$ & .052 & & & \\
vs. & & 155 & $\mathbf{. 0 0 0 *}$ & .961 \\
Faculty & & & & \\
\hline
\end{tabular}

$* p<.05$

Survey item ten.

The tenth item on the survey instrument read: Data on workload allocation at this institution is gathered to address equity issues. Academic administrators, $N=36$, had a mean score of 2.81 and faculty members, $N=120$, mean score was 2.33 (see Table 27 ). A t-test was computed and yielded $t=.052, d f=154$, and $p=.012(p<.05)$ (see Table 28). The null hypothesis is therefore rejected; there is a significant difference in the mean scores of the two groups. 
Table 27

Mean Scores for Item 10

\begin{tabular}{lcccc}
\hline \multicolumn{1}{c}{ Group } & $N$ & $M$ & $S D$ & $S E M$ \\
\hline $\begin{array}{l}\text { Academic } \\
\text { administrators }\end{array}$ & 36 & 2.81 & .9667 & .118 \\
Faculty & 120 & 2.33 & .8400 & .088 \\
\hline
\end{tabular}

Table 28

t-test for Item 10

\begin{tabular}{lcccc}
\hline \multicolumn{1}{c}{ Group } & $t$ & $d f$ & $p$ & Mean Difference \\
\hline $\begin{array}{l}\text { Academic } \\
\text { administrators }\end{array}$ & & & & \\
vs. & .052 & 154 & $\mathbf{0 1 2} *$ & .472 \\
Faculty & & & & \\
\hline
\end{tabular}

\section{$* p<.05$}

\section{Survey item eleven.}

The eleventh item on the survey instrument read: The workload allocation structure at this institution is transparent enough to let me know that workload demands are equitable. Academic administrators, $N=36$, had a mean score of 2.75 and faculty members, $N=121$, mean score was 2.17 (see Table 29). A t-test was computed and yielded $t=.052, d f=155$, and $p=.004$ $(p<.05)$ (see Table 30). The null hypothesis is therefore rejected; there is a significant difference in the mean scores of the two groups. 
Table 29

Mean Scores for Item 11

\begin{tabular}{lcccc}
\hline \multicolumn{1}{c}{ Group } & $N$ & $M$ & $S D$ & $S E M$ \\
\hline $\begin{array}{l}\text { Academic } \\
\text { administrators }\end{array}$ & 36 & 2.75 & 1.0104 & .155 \\
Faculty & 121 & 2.17 & .9651 & .092 \\
\hline
\end{tabular}

Table 30

t-test for Item 11

\begin{tabular}{lcccc}
\hline \multicolumn{1}{c}{ Group } & $t$ & $d f$ & $p$ & Mean Difference \\
\hline $\begin{array}{l}\text { Academic } \\
\text { administrators }\end{array}$ & & & & \\
vs. & .052 & 155 & $\mathbf{0 0 4} *$ & .585 \\
Faculty & & & & \\
\hline
\end{tabular}

$* p<.05$

\section{Survey item twelve.}

The twelfth item on the survey instrument read: The workload allocation process in my department is transparent and equitable. Academic administrators, $N=36$, had a mean score of 3.36 and faculty members, $N=121$, mean score was 2.55 (see Table 31 ). A t-test was computed and yielded $t=.052, d f=155$, and $p=.000(p<.05)$ (see Table 32). The null hypothesis is therefore rejected; there is a significant difference in the mean scores of the two groups. 
Table 31

Mean Scores for Item 12

\begin{tabular}{lcccc}
\hline \multicolumn{1}{c}{ Group } & $N$ & $M$ & $S D$ & $S E M$ \\
\hline $\begin{array}{l}\text { Academic } \\
\text { administrators }\end{array}$ & 36 & 3.36 & 1.1341 & .220 \\
Faculty & 121 & 2.55 & 1.4990 & .103 \\
\hline
\end{tabular}

Table 32

t-test for Item 12

\begin{tabular}{lcccc}
\hline \multicolumn{1}{c}{ Group } & $t$ & $d f$ & $p$ & Mean Difference \\
\hline $\begin{array}{l}\text { Academic } \\
\text { administrators }\end{array}$ & & & & \\
VS. & .052 & 155 & $\mathbf{0 0 0 *}$ & .816 \\
Faculty & & & &
\end{tabular}

$* p<.05$

Survey item thirteen.

The thirteenth item on the survey instrument read: The workload allocation model at this institution is fair. Academic administrators, $N=36$, had a mean score of 3.08 and faculty members, $N=121$, mean score was 2.48 (see Table 33). A t-test was computed and yielded $t=.052, d f=155$, and $p=.010(p<.05)$ (see Table 34$)$. The null hypothesis is therefore rejected; there is a significant difference in the mean scores of the two groups. 
Table 33

Mean Scores for Item 13

\begin{tabular}{lcccc}
\hline \multicolumn{1}{c}{ Group } & $N$ & $M$ & $S D$ & $S E M$ \\
\hline $\begin{array}{l}\text { Academic } \\
\text { administrators }\end{array}$ & 36 & 3.08 & 1.2332 & .133 \\
Faculty & 121 & 2.48 & .8916 & .112 \\
\hline
\end{tabular}

Table 34

t-test for Item 13

\begin{tabular}{lcccc}
\hline \multicolumn{1}{c}{ Group } & $t$ & $d f$ & $p$ & Mean Difference \\
\hline $\begin{array}{l}\text { Academic } \\
\text { administrators }\end{array}$ & & & & \\
vs. & .052 & 155 & $\mathbf{. 0 1 0 *}$ & .604 \\
Faculty & & & & \\
\hline $\boldsymbol{*} \boldsymbol{p}<\mathbf{0 5}$ & & &
\end{tabular}

\section{Survey item fourteen.}

The fourteenth item on the survey instrument read: Faculty workload plans do NOT reflect the number of tasks faculty members do at my university. Scoring for this reverse order item was adjusted. Academic administrators, $N=36$, had a mean score of 3.86 and faculty members, $N=120$, mean score was 4.24. A t-test was computed and yielded $t=.052, d f=154$, and $p=.068(p>.05)$. The null hypothesis is not rejected; there is no significant difference in the mean scores of the two groups.

\section{Survey item fifteen.}

The fifteenth item on the survey instrument read: There must be a differential in faculty workloads at this institution for fairness to occur. Academic administrators, $N=36$, had a mean 
score of 3.92 and faculty members, $N=121$, mean score was 3.90. A t-test was computed and yielded $t=.052, d f=155$, and $p=.922(p>.05)$. The null hypothesis is not rejected; there is no significant difference in the mean scores of the two groups.

\section{Survey item sixteen.}

The sixteenth item on the survey instrument read: Preferential treatment in workload is given to some faculty members at this institution. Academic administrators, $N=36$, had a mean score of 3.53 and faculty members, $N=121$, mean score was 3.76. A t-test was computed and yielded $t=.052, d f=155$, and $p=.235(p>.05)$. The null hypothesis is not rejected; there is no significant difference in the mean scores of the two groups.

\section{Survey item seventeen.}

The seventeenth item on the survey instrument read: It is fair to use credit-hours as a comparative metric for research and service. Academic administrators, $N=36$, had a mean score of 2.83 and faculty members, $N=121$, mean score was 2.63 . A t-test was computed and yielded $t=.052, d f=155$, and $p=.323(p>.05)$. The null hypothesis is not rejected; there is no significant difference in the mean scores of the two groups.

\section{Survey item eighteen.}

The eighteenth item on the survey instrument read: The faculty allocation model favors some faculty over others within my department. Academic administrators, $N=36$, had a mean score of 3.17 and faculty members, $N=119$, mean score was 3.45. A t-test was computed and yielded $t=.052, d f=153$, and $p=.171(p>.05)$. The null hypothesis is not rejected; there is no significant difference in the mean scores of the two groups. 


\section{Survey item nineteen.}

The nineteenth item on the survey instrument read: Faculty members at this institution are fairly compensated for their contributions in all areas of their workload. Academic administrators, $N=36$, had a mean score of 2.50 and faculty members, $N=121$, mean score was 2.11. A t-test was computed and yielded $t=.052, d f=156$, and $p=.056(p>.05)$. The null hypothesis is not rejected; there is no significant difference in the mean scores of the two groups.

\section{Survey item twenty.}

The twentieth item on the survey instrument read: Workload allocation models at this institution do NOT accurately reflect the true time it takes to complete tasks. Scoring for this reverse order question was adjusted. Academic administrators, $N=36$, had a mean score of 3.61 and faculty members, $N=120$, mean score was 4.13 (see Table 35 ). A t-test was computed and yielded $t=.052, d f=154$, and $p=.018(p<.05)$ (see Table 36). The null hypothesis is therefore rejected; there is a significant difference in the mean scores of the two groups. Table 35

Mean Scores for Item 20

\begin{tabular}{lcccc}
\hline \multicolumn{1}{c}{ Group } & $N$ & $M$ & $S D$ & SEM \\
\hline $\begin{array}{l}\text { Academic } \\
\text { administrators }\end{array}$ & 36 & 3.61 & 1.1614 & .107 \\
Faculty & 120 & 4.13 & .8017 & .106 \\
\hline
\end{tabular}


Table 36

t-test for Item 20

\begin{tabular}{lcccc}
\hline \multicolumn{1}{c}{ Group } & $t$ & $d f$ & $p$ & Mean Difference \\
\hline $\begin{array}{l}\text { Academic } \\
\text { administrators }\end{array}$ & & & & \\
vs. & .052 & 154 & $\mathbf{. 0 1 8 *}$ & .514 \\
Faculty & & & & \\
\hline $\boldsymbol{*} \boldsymbol{p}<\mathbf{0 5}$ & & &
\end{tabular}

\section{Survey item twenty-one.}

The twenty-first item on the survey instrument read: By requiring faculty to spend more time in the classroom teaching larger class sizes, this institution sacrifices some portion of research and publication productivity. Academic administrators, $N=36$, had a mean score of 3.78 and faculty members, $N=121$, mean score was 3.83 . A t-test was computed and yielded $t=.052, d f=155$, and $p=.785(p>.05)$. The null hypothesis is not rejected; there is no significant difference in the mean scores of the two groups.

\section{Survey item twenty-two.}

The twenty-second item on the survey instrument read: Faculty are rewarded more for research and publications than for teaching at this university. Academic administrators, $N=36$, had a mean score of 3.92 and faculty members, $N=122$, mean score was 4.02 . A t-test was computed and yielded $t=.052, d f=156$, and $p=.633(p>.05)$. The null hypothesis is not rejected; there is no significant difference in the mean scores of the two groups.

\section{Survey item twenty-three.}

The twenty-third item on the survey instrument read: Faculty at this institution are expected to place teaching obligations before scholarship and service. Academic administrators, 
$N=36$, had a mean score of 2.61 and faculty members, $N=120$, mean score was 2.54 . A t-test was computed and yielded $t=.052, d f=154$, and $p=.744(p>.05)$. The null hypothesis is not rejected; there is no significant difference in the mean scores of the two groups.

\section{Survey item twenty-four.}

The twenty-fourth item on the survey instrument read: The comparison of teaching credit-hours to the amount of research and service faculty conduct is arbitrary at this institution. Academic administrators, $N=35$, had a mean score of 3.17 and faculty members, $N=120$, mean score was 3.46. A t-test was computed and yielded $t=.052, d f=153$, and $p=.163(p>.05)$. The null hypothesis is not rejected; there is no significant difference in the mean scores of the two groups.

\section{Survey item twenty-five.}

The twenty-fifth item on the survey instrument read: At this institution, scholarship, teaching, and service are rewarded equally. Academic administrators, $N=36$, had a mean score of 1.89 and faculty members, $N=120$, mean score was 1.98 . A t-test was computed and yielded $t=.052, d f=154$, and $p=.529(p>.05)$. The null hypothesis is not rejected; there is no significant difference in the mean scores of the two groups.

\section{Survey item twenty-six.}

The twenty-sixth item on the survey instrument read: Faculty members at this institution are expected to be productive in three primary areas (teaching, research, and service) whereas they are evaluated by their teaching load alone by those outside the institution. Academic administrators, $N=36$, had a mean score of 2.50 and faculty members, $N=120$, mean score was 
2.60. A t-test was computed and yielded $t=.052, d f=154$, and $p=.636(p>.05)$. The null hypothesis is not rejected; there is no significant difference in the mean scores of the two groups.

\section{Survey item twenty-seven.}

The twenty-seventh item on the survey instrument read: The faculty members at this institution work in an increasingly demanding environment. Academic administrators, $N=36$, had a mean score of 4.31 and faculty members, $N=121$, mean score was 4.33 . A t-test was computed and yielded $t=.052, d f=155$, and $p=.874(p>.05)$. The null hypothesis is not rejected; there is no significant difference in the mean scores of the two groups.

\section{Survey item twenty-eight.}

The twenty-eighth item on the survey instrument read: Workload differences at this institution cause problems among faculty members. Academic administrators, $N=35$, had a mean score of 3.29 and faculty members, $N=121$, mean score was 3.49. A t-test was computed and yielded $t=.052, d f=154$, and $p=.240(p>.05)$. The null hypothesis is not rejected; there is no significant difference in the mean scores of the two groups.

\section{Survey item twenty-nine.}

The twenty-ninth item on the survey instrument read: Faculty members at this institution feel the time needed to invest in research is underappreciated. Academic administrators, $N=36$, had a composite mean score of 3.42 and faculty members, $N=120$, composite mean score was 3.61. A t-test was computed and yielded $t=.052, d f=154$, and $p=.352(p>.05)$. The null hypothesis is not rejected; there is no significant difference in the composite mean scores of the two groups. 


\section{Survey item thirty.}

The thirtieth item on the survey instrument read: Faculty members at this institution are dissatisfied when comparing their workload and salary to those outside academe. Academic administrators, $N=35$, had a mean score of 3.43 and faculty members, $N=120$, mean score was 3.77. A t-test was computed and yielded $t=.052, d f=153$, and $p=.097(p>.05)$. The null hypothesis is not rejected; there is no significant difference in the mean scores of the two groups.

\section{Survey item thirty-one.}

The thirty-first item on the survey instrument read: The administration at this institution adequately values faculty productivity. Academic administrators, $N=36$, had a mean score of 3.50 and faculty members, $N=120$, mean score was 3.05 (see Table 37 ). A t-test was computed and yielded $t=.052, d f=154$, and $p=.028(p<.05)$ (see Table 38). The null hypothesis is therefore rejected; there is a significant difference in the mean scores of the two groups.

Table 37

Mean Scores for Item 31

\begin{tabular}{lcccc}
\hline \multicolumn{1}{c}{ Group } & $N$ & $M$ & $S D$ & $S E M$ \\
\hline $\begin{array}{l}\text { Academic } \\
\text { administrators }\end{array}$ & 36 & 3.50 & 1.0408 & .172 \\
Faculty & 120 & 3.05 & 1.0153 & .095 \\
\hline
\end{tabular}


Table 38

t-test for Item 31

\begin{tabular}{lcccc}
\hline \multicolumn{1}{c}{ Group } & $t$ & $d f$ & $p$ & Mean Difference \\
\hline $\begin{array}{l}\text { Academic } \\
\text { administrators }\end{array}$ & & & & \\
vs. & .052 & 154 & $\mathbf{. 0 2 8 *}$ & .450 \\
Faculty & & & & \\
\hline $\boldsymbol{*} \boldsymbol{p}<\mathbf{0 5}$ & & &
\end{tabular}

\section{Survey item thirty-two.}

The thirty-second item on the survey instrument read: Over time, faculty at this institution become less content with university support of salary as it compares to workloads. Academic administrators, $N=36$, had a mean score of 3.78 and faculty members, $N=121$, mean score was 3.94. A t-test was computed and yielded $t=.052, d f=155$, and $p=.262(p>.05)$. The null hypothesis is not rejected; there is no significant difference in the mean scores of the two groups.

\section{Survey item thirty-three.}

The thirty-third item on the survey instrument read: Faculty morale at this institution has improved because of the consistent application of faculty workloads. Academic administrators, $N=36$, had a mean score of 2.67 and faculty members, $N=119$, mean score was 2.38 . A t-test was computed and yielded $t=.052, d f=153$, and $p=.123(p>.05)$. The null hypothesis is not rejected; there is no significant difference in the mean scores of the two groups.

\section{Survey item thirty-four.}

The thirty-fourth item on the survey instrument read: The publication of teaching workloads results in improved faculty morale at this institution. Academic administrators, $N=36$, had a mean score of 2.83 and faculty members, $N=120$, mean score was 2.64 . A t-test was 
computed and yielded $t=.052, d f=154$, and $p=.201(p>.05)$. The null hypothesis is not rejected; there is no significant difference in the mean scores of the two groups.

\section{Survey item thirty-five.}

The thirty-fifth item on the survey instrument read: Faculty at this institution feel pressured to undertake tasks that are not part of their workload plan. Academic administrators, $N=36$, had a mean score of 3.47 and faculty members, $N=121$, mean score was 3.73. A t-test was computed and yielded $t=.052, d f=155$, and $p=.188(p>.05)$. The null hypothesis is not rejected; there is no significant difference in the mean scores of the two groups.

\section{Summary}

This chapter has depicted the results of a survey developed to offer insight into academic administrator and faculty member perceptions of the workload allocation process. Specifically, the results have been shown by domains intended to answer each of the five research questions, a composite mean score of all responses, and the results comparing two groups' responses to each individual item.

In general terms of the results obtained, the most interesting outcome was that one entire dimension had every item within it show statistically significant different perceptions between academic administrators and faculty members. Three of the remaining four domains had standalone items with significant differences, but there was not a significant difference in the overall domain. One domain had academic administrators and faculty members agreeing similarly to each of the domain items.

Chapter Five will examine the meaning of the results and how this study may serve to improve the workload allocation process for both academic administrators and faculty members. 
The conclusion will include a discussion of why it is important for higher education administrative leaders to be aware of differences in the workload allocation process, as well as recommendations for future research. 


\section{Chapter Five: Discussion}

This study compared academic administrator and faculty member perceptions of the workload allocation process at education programs offering doctorate degrees at High Research Carnegie Classification institutes in the southeastern United States. Of the five domains examined in this study, a clear picture emerges when one considers that each and every item included in one domain, workload allocation equity and transparency, showed significant differences between academic administrators' and faculty members' responses. These results suggest that the research does give insight into the incongruent perceptions people have of the workload allocation process.

Previous research has suggested that although both academic administrators and faculty members agree in principle that workload equity is desirable, the practicality of assuring it is difficult. As Vardi's 2009 research indicated, academic administrators feel as if there are limitations to being equitable in developing faculty workloads. Cited among the limitations are faculty expertise and availability, levels of appointment, competence, experience, career aspirations, preferences for courses, and student preferences. The natural outcome of these limitations is that some faculty may receive preferential workload, even with a well-developed workload allocation process. Houston et al. (2006) study also recognized faculty expertise as a factor in developing workload plans, but also addressed the overall complexity of universities as organizations.

Institutional missions, institutional needs, accreditation criteria, research demands, and students' needs all have a role in developing workload allocation (Houston et al., 2006, Lau, 1996). For many academic administrators, institutional demands trump the demands of 
workload equity. Needs based workload allocation may result in increases in faculty workload, which in turn leads to faculty members comparing workloads for equity (Durham et al., 2007).

The result of these two different approaches, institutional needs versus equitable and transparent workloads for faculty members, may be the reason for the differences exposed in this study; the two groups simply have different motives in seeking resource allocation. On one hand, academic administrators may view faculty as a resource tool through which institutional needs may be met, whereas faculty members view their time as their resource - a valuable asset which needs to be used in the most efficient manner possible, as long as it is comparatively equitable to their colleagues.

\section{Explanations of Significantly Different Responses}

In each of the items within the domain measuring perceptions of workload equity and transparency, academic administrators indicated more equitable and transparent processes than did faculty members. For example, faculty members indicated that tenure and promotion criteria are too broad at their respective institutions; academic administrators disagreed.

On the question of whether faculty members have a clear understanding of how academic administrators determine faculty workload, the two groups again have different opinions. Academic administrators felt as if faculty members understand the process academic administrators go through in determining faculty workload. Faculty members, however, indicated less certainty with the process; they do not understand how their workload is determined.

When asked whether data are gathered to address faculty workload equity, faculty members indicated it is not, whereas academic administrators indicated it is. If it is, perhaps the 
process is not transparent enough to keep faculty members informed. Increased transparency may aid in closing the gap on the question of whether institutional workload allocation processes allow faculty members know that workload demands are equitable.

Faculty members who responded did not feel as if the workload allocation structure is transparent at the institutional level. Again, academic administrators indicated otherwise, that the structure is transparent enough to assure equity. Likewise, when asked whether departmental workload allocation processes are transparent and equitable, faculty members responded negatively. Academic administrators, however, indicated that departmental workload allocation processes are transparent and equitable.

Academic administrators believe the workload allocation process at their institutions and within their departments are equitable. However, the very persons for whom the workload allocation process applies disagree. Faculty members feel as if the equity and transparency of the workload allocation process at both the institutional level and the departmental level need improvement. The issue of workload allocation equity and transparency was not isolated as the only area of disagreement between academic administrators and faculty members. Other standalone items from the survey also indicated disparity between the two groups.

Faculty members do not agree with academic administrators when asked whether the development of the workload allocation model their respective institutions includes all stakeholders. Academic administrators feel as if all stakeholders are included in the process, whereas faculty members indicated they feel as if some stakeholders are not included in the process. Faculty members also indicated that they feel less assured than do academic administrators about the fairness of the workload allocation models at their respective 
institutions. Finally, the direct relationship between faculty members and academic administrators indicated gaps which, if decreased, may go far in the process and understanding of allocating workload.

Faculty members feel as if academic administrators do not fully understand the true time it takes to complete the tasks expected of their department and institutional academic staff. Conversely, academic administrators imply they understand the time requirements for various faculty duties. In responding to a related item, faculty members feel as if academic administrators at their institutions do not adequately value faculty productivity. Academic administrators disagree; they feel as if the productivity of faculty is appreciated.

With the information gleaned from this research, higher education academic administrators can identify areas for improvement in the workload allocation process, the result of which is a better defined process, a reduction in perceived shortcomings, and a more productive environment for faculty and administration.

\section{Implications for Higher Education Leaders}

With four of the five domains each having at least one area in which faculty and academic administrators differ in perceptions of the workload allocation process, the potential for improvement is undeniable. Through collaboration, academic administrators and faculty may begin to reconcile their perceived differences by examining the direction of the differences and using the outcomes for improved processes.

For example, under the domain for workload allocation value, faculty members indicated stakeholders are less involved with the workload allocation process than what academic administrators did. Academic administrators should consult faculty members for an indication of 
what stakeholders are being excluded in the process. It may be that all stakeholders are included and that the faculty members are unaware of their inclusion, or that academic administrators are excluding stakeholders whom faculty members feel are important to the process.

In the fairness domain, faculty members indicated the workload allocation at their institutions as being less fair than what academic administrators indicated. Academic administrators should determine what part of the process faculty members feel is unfair. Only after establishing a mutual understanding of the process' fairness can the parties move toward closing the gap.

As indicated in the data, another perceived shortcoming in the fairness domain is that the workload allocation models do not accurately reflect the true time it takes to complete tasks at respective institutions. Both academic administrators and faculty members agreed that task time is not accurately reflected in the workload allocation process, with faculty members responding with greater agreement. Academic administrators should work with respective academic unit faculty members to establish times more accurately reflective of actual times it takes to conduct tasks contained and measured in workload allocation.

Academic administrators indicated stronger agreement with the statement in the job satisfaction domain that administration at respective institutions adequately value faculty productivity. If faculty members feel as if their work is underappreciated, academic administrators should make an effort to determine how they can more clearly show faculty members that their work is valued.

Significant differences occurred for each item in the equity and transparency domain, so this domain may require additional attention from academic administrators. If faculty members 
perceive tenure and promotion criteria as being too broad, academic administrators should gain an understanding of what faculty members specifically feel needs to be addressed to narrow the criteria. Additionally, academic administrators should make a concerted effort to determine what part of the workload allocation process faculty members do not understand. Faculty members and academic administrators held different perceptions on whether their institutions gather data on workload allocation in order to address equity issues. This particular item is based on fact; either an institution does or does not gather the data. Differences within this domain can be reduced by communicating the existence or non-existence of the institution's practice on gathering the data to address equity issues.

Lastly, both academic administrators and faculty members indicated that workload allocation structures at institutional level are not transparent, with faculty members indicating more strongly that the process is not transparent. When questioned about the same on the departmental level, academic administrators indicated transparency whereas faculty members maintained a lack of transparency. Academic administrators' must be cognizant that faculty members perceive their academic units' workload allocation structure in the same light as they do the institutions when it comes to transparency. If academic administrators consider their own academic unit's workload allocation process as transparent but the institution's process as lacking transparency, they should reconcile the difference through discussion with faculty members to determine what the academic unit does differently than, or the same as, the institution when it comes to workload allocation transparency. 


\section{Recommendations for Further Research}

The results of this study offer insight into several possibilities for additional research. For example, this study focused on education programs offering doctorate degrees at Carnegie Classified High Research institutions in the southeast region of the United States. Comparative studies using a combination of substitutive variables, for example other regions, disciplines, or Carnegie Classifications may be useful to determine the extent of the disparities. The continued use of the instrument developed for this research will offer additional validity and reliability.

Additionally, while the focus of this research was whether differences existed between two groups' perceptions, qualitative research could be developed to investigate the question of why there are perceived differences. Likewise, research could be developed to identify both groups' perceptions of which domain from this study is considered to be the most important in the workload allocation process. Ultimately, continued research may lead to the development and identification best practices for the workload allocation process.

Institutes of higher education are labor intensive by nature. The process of labor division, or workload allocation as it is referred in higher education, is a regular topic of debate. It is critical that the primary entities involved in the process, academic administrators and faculty members, have an understanding of each other's perceptions of the process. For faculty, a more complete picture may emerge of all factors considered in the workload allocation process. For higher education academic administrators, the continued research into identifying perceptual differences will improve the workload allocation process and its' implementation. 


\section{References}

Allen, H.L. (1996). Faculty workload and productivity in the 1990s: Preliminary findings. In The NEA 1996 Almanac of Higher Education (1996 pp. 21-34) Washington, D.C.: National Education Association.

Burns, A.C., \& Bush, R.F. (2008). Basic marketing research: Using Microsoft Excel® data analysis ( $2^{\text {nd }}$ Ed). Upper Saddle River, NJ: Pearson Prentice Hall.

Carnegie Foundation for the Advancement of Teaching (n.d.). Retrieved from http://classifications.carnegiefoundation.org/descriptions/basic.php

Clark, K. (2009, January 27). The recession hits college campuses. U.S. News \& World Report, Retrieved from http://www.usnews.com/education/articles/2009/01/27/the-recession-hitscollege-campuses

Comm, C. L., \& Mathaisel, D.F. (2003). A case study of the implications of faculty workload and compensation for improving academic quality. International Journal of Educational Management, 17(5), 200 - 210. doi:10.1108/09513540310484922

Creswell, J. W. (2003). Research design ( $2^{\text {nd }}$ Ed). Thousand Oaks, CA: Sage.

Durham, S., Merrit, J., \& Sorrell, J. (2007). Implementing a new faculty workload formula. Nursing Education Perspectives, 28(4), 184-189.

Ehrlrich, T. (2003). The credit-hour and faculty instructional workload. New Directions for Higher Education, 2003, Summer(122), 45-55.

Eunjoo, O. \& Suhong, P. (2009). How are universities involved in blended instruction? Journal of Educational Technology \& Society, 12(3), 327-342. 
Fairweather, J. S. (1996). Faculty work and public trust: Restoring the value of teaching and public service in American academic life. Needham Heights, MA: Longwood Division, Allyn and Bacon.

Fisher, M. (1999). Faculty workload ruled non-negotiable in Ohio. Black Issues in Higher Education, 16(20), 18.

Freedenthal, S., Potter, C., \& Grinstein-Weiss, M. (2008). Institutional supports for faculty scholarship; A national survey of social work. Social Work Research, 32(4), 220-230.

Green, H.C., O’Connor, K.A., Good, A.J., Ledford, C.C., Peel, B.B., \& Zhang, G. (2008). Building a support system toward tenure: challenges and needs of tenure-track faculty in colleges of education. Mentoring and Tutoring: Partnership in Learning, 16(4), 429447. doi:10.1080/13611260802433791

Green, R. G. (2008). Tenure and promotion decisions: The relative importance of teaching, scholarship, and service. Journal of Social Work Education, 44(2), 117-127.

Heffernan, J.M. (1973). The credibility of the credit-hour: the history, use, and shortcomings of the credit system. The Journal of Higher Education, 44(1), 61-72.

Hersey, P., Blanchard, K.H., \& Johnson, D.E. (1996). Management of organizational behavior: Utilizing human resources $\left(6^{\text {th }}\right.$ Ed). Upper Saddle River, NJ: Prentice Hall.

Heydinger, R.B., \& Simsek, H. (1992). An agenda for reshaping faculty productivity: State policy and college learning. (Report No. PS-92-3). Denver: State Higher Education Executive Officer.

Hill, R. (2009, August). Economy and the aging professoriate. Academic Leader, 25(8), 2-3. 
Himes, A.C. (2005, March). Myths, realities, and secrets of academic administration. Academic Leader, 21(3), 1-2.

Houston, D.J., Meyer, L.H., \& Paewai, S. (2006). Academic staff workloads and job satisfaction: Expectations and values in academe. Journal of Higher Education Policy \& Management, 28(1), 17-30.

June, A.W. (2008). Teaching, research, and service by the numbers at Boise State. Chronicle of Higher Education, 54(45), B24-B25.

Ladd, Jr., E.C. (1979). The work experience of American college professors: Some data and an argument. Current Issues in Higher Education. Washington DC: American Association of Higher Education.

Lau, R.S.M. (1996). Evaluating faculty workload: An application process. Journal of Education for Business, 72(2), 94-97.

Lumpkin, A. (2004). Enhancing the effectiveness of department chairs. The Journal of Physical Education, Recreation \& Dance, 75(9), 44-49.

Managing Faculty Workload to Reflect Differences Among Disciplines. (2005, September). Academic Leader, 21(9), 3.

Massey, W.F. \& Wilger, A.K. (1992). Productivity in postsecondary education: A new approach. Education Evaluation and Policy Analysis, 14(4). 361-376.

Mayes, L.D. (1998). Assessing faculty workload: A review of the University of Kentucky Community College System. Community College Journal of Research \& Practice, 22(2), $145-151$. 
McGurdy, S, \& Zegwaard, K.E. (2009). Faculty voices: What faculty think about work integrated learning. Journal of Cooperative Education \& Internships, 43(1), 36-53.

Porter, S.R., \& Umbach, P.D. (2001). Analyzing faculty workload data using multilevel modeling. Research in Higher Education, 42(2), 171-196.

Research on Faculty and Institutions. (2002). ASHE-ERIC Higher Education Report, 29(4), $55-74$

Rosser, V. (2004). Faculty members' intention to leave: a national study on their worklife and satisfaction. Research in Higher Education, 45(3), 285-309.

Russell, A.B. (1992). Faculty workloads: State and system perspectives. State policy and college learning. (Report No. PS-92-1). Denver: State Higher Education Executive Officers.

Seaberg, J.R. (1998). Faculty reports of workload: Results of a national survey. Journal of Social Work Education, 34(1), 7-19.

Sudman, S. \& Blair, E. (1998). Marketing research: A problem-solving approach. Boston, MA: Irwin McGraw-Hill.

Sumner, K.P., \& Brewer, R.G. (2006). Benchmarking instructional costs and productivity: The Kansas Study. New Directions for Community Colleges, 2006(134), 5-13.

Suskie, L.A. (1996). Questionnaire survey research: What works (2 ${ }^{\text {nd }}$ Ed). Tallahassee, FL: Association for Institutional Research.

Vardi, I. (2009). Impacts of different types of workload allocation models on academic satisfaction and working life. Higher Education, 57(4), 499-508.

Voignier, R.R., Hermann, C.P., \& Brouse, S.H. (1998). Development of a faculty work load formula: The teaching component. Nurse Educator, 23(4), 35-39. 
What's Driving Your Instructional Cost? (2002). ASHE-ERIC Higher Education Report, 28(5), 7-29.

Wilson, R. (1999). Supreme court says Ohio can bypass collective bargaining on faculty workloads. Chronicle of Higher Education, 45(30), A19.

Wyant, J.F. \& Morrison, P. D. (1972). A faculty workload survey. Journal of Education for Librarianship, 12(3), 155-161. 
Appendices A, B, C, D, E, F, \& G 


\section{Appendix A}

\section{Domains and Items}

Domain 1: Perceptions of Workload Allocation Model Value

1. The development of the workload allocation model at this institution includes all stakeholders.

2. There is an imbalance between faculty desires and institutional needs at this institution.

3. The publication of teaching workloads results in greater awareness of others' responsibilities at this institution.

4. Increases in faculty workload contribute to lower instructional costs at this institution.

5. Workload allocation models are essential to the success of this institution.

6. The workload norms at this institution were developed due to competition for faculty from other institutions.

7. The primary purpose of the workload policy at this institution is to accommodate the present and future needs including its continuous accreditation and improvement mandates.

Domain 2: Perceptions of Workload Allocation Model Equity and Transparency.

1. The criteria used for tenure and promotion at my university are too broad.

2. Faculty members have a clear understanding of how administrators determine faculty workload.

3. Data on workload allocation at this institution is gathered to address equity issues.

4. The workload allocation structure at this institution is transparent enough to let me know that workload demands are equitable 
5. The workload allocation process in my department is transparent and equitable.

Domain 3: Perceptions of Workload Allocation Model Fairness.

1. The workload allocation model at this institution is fair.

2. My workload plan does NOT reflect the number of tasks I actually do at my university.

3. There must be a differential in faculty workloads at this institution for fairness to occur.

4. Preferential treatment in workload is given to some faculty members at this institution.

5. It is fair to use credit-hours as a comparative metric for research and service.

6. The workload allocation model favors some faculty over others within my department.

7. Faculty members at this institution are fairly compensated for their contributions in all areas of their workload.

8. Workload allocation models at this institution do NOT accurately reflect the true time it takes to complete tasks.

Domain 4: Perceptions Workload Allocation Model Components.

1. By requiring faculty members to spend more time in the classroom teaching larger class sizes, this institution sacrifices some portion of research and publication productivity.

2. Faculty members are rewarded more for research and publications than for teaching at this institution.

3. Faculty members at this institution are expected to place teaching obligations before scholarship and service.

4. The comparison of teaching credit-hours to the amount of research and service faculty conduct is arbitrary at this institution.

5. At this institution, research, teaching, and service are rewarded equally. 
6. Faculty members at this institution are expected to be productive in three primary areas (teaching, research, and service) whereas they are evaluated by their teaching load alone by those outside the institution.

Domain 5: Perceptions of Workload Allocation Model Effects on Job Satisfaction.

1. The faculty members at this institution work in an increasingly demanding environment.

2. Workload differences at this institution cause problems among faculty members.

3. Faculty members at this institution feel the time needed to invest in research is underappreciated.

4. Faculty members at this institution are dissatisfied when comparing their workload and salary to those outside academe.

5. The administration at this institution adequately values faculty productivity.

6. Over time, faculty at this institution become less content with university support of salary as it compares to workloads.

7. Faculty morale at this institution has improved because of the consistent application of faculty workloads.

8. The publication of teaching workloads results in improved faculty morale at this institution.

9. Faculty at this institution feel pressured to undertake tasks that are not part of their workload plan. 


\section{Appendix B}

\section{Pauls \& Chapman Instrument for Measuring Perceptions of Workload Allocation Process}

On a scale of 1 to 5 (Strongly Agree to Strongly Disagree) Please indicate your level of agreement or disagreement with the following statements:

$\begin{array}{ccccc}\text { Strongly } & \text { Somewhat } & \text { Neither Agree } & \text { Somewhat } & \text { Strongly } \\ \text { Disagree } & \text { Disagree } & \text { nor Disagree } & \text { Agree } & \text { Agree } \\ 1 & 2 & 3 & 4 & 5\end{array}$

1. The development of the workload allocation model at this institution includes all stakeholders.

2. There is an imbalance between faculty desires and institutional needs at this institution.

3. The publication of teaching workloads results in greater awareness of others' responsibilities at this institution.

4. Increases in faculty workload contribute to lower instructional costs at this institution.

5. Workload allocation models are essential to the success of this institution.

6. The workload norms at this institution were developed due to competition for faculty from other institutions.

7. The primary purpose of the workload policy at this institution is to accommodate the present and future needs including its continuous accreditation and improvement mandates.

8. The criteria used for tenure and promotion at my university are too broad.

9. Faculty members have a clear understanding of how administrators determine faculty workloads.

10. Data on workload allocation at this institution are gathered to address equity issues.

11. The workload allocation structure at this institution is transparent enough to let me know that workload demands are equitable

12. The workload allocation process in my department is transparent and equitable.

13. The workload allocation model at this institution is fair. 
14. My workload plan does NOT reflect the number of tasks I actually do at my university.

15. There must be a differential in faculty workloads at this institution for fairness to occur.

16. Preferential treatment in workload is given to some faculty members at this institution.

17. It is fair to use credit-hours as a comparative metric for research and service.

18. The workload allocation model favors some faculty over others within my department.

19. Faculty members at this institution are fairly compensated for their contributions in all areas of their workload.

20. Workload allocation models at this institution do NOT accurately reflect the true time it takes to complete tasks.

21. By requiring faculty to spend more time in the classroom teaching larger class sizes, this institution sacrifices some portion of research and publication productivity.

22. Faculty are rewarded more for research and publications than for teaching at this institution.

23. Faculty at this institution are expected to place teaching obligations before scholarship and service.

24. The comparison of teaching credit-hours to the amount of research and service faculty conduct is arbitrary at this institution.

25. At this institution, scholarship teaching and service are rewarded equally.

26. Faculty members at this institution are expected to be productive in three primary areas (teaching, research, and service) whereas they are evaluated by their teaching load alone by those outside the institution.

27. The faculty members at this institution work in an increasingly demanding environment.

28. Workload differences at this institution cause problems among faculty members.

29. Faculty members at this institution feel the time needed to invest in research is underappreciated.

30. Faculty members at this institution are dissatisfied when comparing their workload and salary to those outside academe. 
31. The administration at this institution adequately values faculty productivity.

32. Over time, faculty at this institution become less content with university support of salary as it compares to workloads.

33. Faculty morale at this institution has improved because of the consistent application of faculty workloads.

34. The publication of teaching workloads results in improved faculty morale at this institution.

35. Faculty at this institution feel pressured to undertake tasks that are not part of their workload plan.

What is your primary role at your institution?

(1) Administrator

(2) Faculty Member

If you are a Faculty Member, are you

(1) Tenured

(2) Tenure Track

(3) Term Contract

How many years have you served as a(n) at your institution?

(1) $1-5$

(2) 6-10

(3) $11-15$

(4) $16-20$

(5) $>20$

For statistical purposes, for which of the following Carnegie Classification High Research institutions are you employeed?

(List of 19 Carnegie Classified High Research Universities in SE United States) 


\section{Appendix C}

\section{Initial Survey Request}

\section{Dear Participant,}

Please consider this request to contribute to a research project to compare perceptions of faculty and academic administrators in an effort to make workload allocation more equitable, fair, and streamlined for the people who have to administer it. The results of this research will aid in understanding differences between the viewpoints of two primary sets of stakeholders in workload allocation.

The instrument used to measure these perceptions will take approximately 7-I0 minutes to complete, but the result for this time invested could help countless faculty and academic administrators. You may skip any item on the survey and may quit at any time. Participant identities will remain confidential in the research report, with responses being reported in the aggregate. Participation in this research is completely voluntary but also greatly appreciated, and there is no negative consequence if you choose not to participate. Participation in this research is limited to those 18 years of age or older. The West Virginia University Institution Review Board (IRB) has acknowledgement of this study on file.

This project is being conducted as part of the requirements for a doctoral dissertation. If you have any questions about this study, please feel free to contact me or the Primary Investigator, Dr. Paul Chapman, Interim Associate Dean and Associate Professor in the College of Human Resources and Education. Our email addresses are tnpauls@gmail.com and paul.chapman@mail.wvu.edu, respectively. At your request, a summary of the results will be sent to you.

Sincerely and with thanks, Theodore N. Pauls

Doctoral Candidate

Follow this link to the Survey:

$\$\{1: / /$ SurveyLink? $=$ Take the Survey $\}$

Or copy and paste the URL below into your internet browser: $\$\{1: / /$ SurveyURL $\}$

Follow the link to opt out of future emails: $\$\{1: / / O p t O u t L i n k ? d=$ Click here to unsubscribe $\}$ 


\section{Appendix D}

\section{Ten Day Reminder}

\section{Greetings!}

Approximately ten days ago I sent an electronic survey to administrators and faculty members at your institution seeking feedback on the workload allocation process. Your name was among those to whom the survey was sent. Because of confidentiality, I do not know whether you have responded or not. If you have already responded, thank you for your helpful contribution to the research! If you have not yet responded, I would appreciate your valuable feedback for the study.

The survey takes approximately 7 to 10 minutes to complete.

If you have any questions about this study, please feel free to contact either me or the chair of my dissertation committee, Dr. Paul Chapman. Our email addresses are tnpauls@gmail.com and paul.chapman@mail.wvu.edu, respectively.

Sincerely,

Ted Pauls

Doctoral Candidate

\section{Follow this link to the Survey:}

$\$\{1: / /$ SurveyLink?d=Take the Survey $\}$

Or copy and paste the URL below into your internet browser:

$\$\{1: / /$ SurveyURL $\}$

Follow the link to opt out of future emails:

$\$\{1: / / O p t O u t L i n k ? d=$ Click here to unsubscribe $\}$ 


\section{Appendix E}

\section{Second Reminder}

As a faculty member or academic administrator at one of 19 high research instituions in the southeastern United States, your email address was selected for participation on a survey measuring perceptions of faculty workload processes. Participant responses from each university have already been recorded, but the more participation received from each institution, the more accurate the results will be. Your participation woud be greatly appreciated.

\section{-The survey takes approximately 7 to 10 minutes to complete.}

-The survey is confidential and completely voluntary.

-The survey has been approved and is on record with the IRB at West Virginia University.

-The survey will close in the first week of December.

If you have any questions about this study, please feel free to contact either me or the chair of my dissertation committee, Dr. Paul Chapman. Our email addresses are tnpauls@gmail.com and paul.chapman@mail.wvu.edu, respectively.

Your participation is greatly appreciated.

Ted Pauls

Doctoral Candidate

Follow this link to the Survey:

$\$\{1: / /$ SurveyLink? $d=$ Take the Survey $\}$

Or copy and paste the URL below into your internet browser:

$\$\{1: / /$ SurveyURL $\}$

Follow the link to opt out of future emails:

$\$\{1: / / O p t O u t L i n k ? d=$ Click here to unsubscribe $\}$ 


\section{Appendix F}

\section{Two Weeks Remaining Reminder}

Greetings!

The survey is about to close! Please offer your valuable contribution to the study on Faculty and Administrative Perceptions of the Faculty Workload Process.

Response has been very good, but I'd still value input from each of the 380 faculty and administrators to whom the survey was sent. Your response is extremely valuable and entirely confidential.

The survey takes approximately 7-10 minutes to complete, asking your level of agreement on 35 single statements.

Because of confidentiality, I do not know whether you have responded or not. If you have already responded, thank you for your helpful contribution to the research! If you have not yet completed the survey, I would appreciate your valuable feedback for the study.

If you have any questions about this study, please feel free to contact either me or the chair of my dissertation committee, Dr. Paul Chapman. Our email addresses are tnpauls@gmail.com and paul.chapman@mail.wvu.edu, respectively.

Thank you!

Ted Pauls

Doctoral Candidate

Follow this link to the Survey:

$\$\{1: / /$ SurveyLink?d=Take the Survey $\}$

Or copy and paste the URL below into your internet browser:

$\$\{1: / /$ SurveyURL $\}$

Follow the link to opt out of future emails:

$\$\{1: / / O p t O u t L i n k ? d=$ Click here to unsubscribe $\}$ 


\section{Appendix G}

\section{Survey Closing Reminder}

Faculty members and academic administrators,

If you have not completed the survey sent to faculty members and academic administrators at 19 high research institutions, please consider doing so. The survey closes at 5:00 today.

\section{-The survey takes approximately 7 to 10 minutes to complete.}

-The survey is confidential and completely voluntary.

-The survey measures perceptions of the faculty workload processes.

-The survey has been approved and is on record with the IRB at West Virginia University.

If you have any questions about this study, please feel free to contact either me or the chair of my dissertation committee, Dr. Paul Chapman. Our email addresses are tnpauls@gmail.com and paul.chapman@mail.wvu.edu, respectively.

Your participation is greatly appreciated.

Ted Pauls

Doctoral Candidate

Follow this link to the Survey:

$\$\{1: / /$ SurveyLink? $d=$ Take the Survey $\}$

Or copy and paste the URL below into your internet browser:

$\$\{1: / /$ SurveyURL $\}$

Follow the link to opt out of future emails:

$\$\{1: / / O p t O u t L i n k ? d=$ Click here to unsubscribe $\}$ 